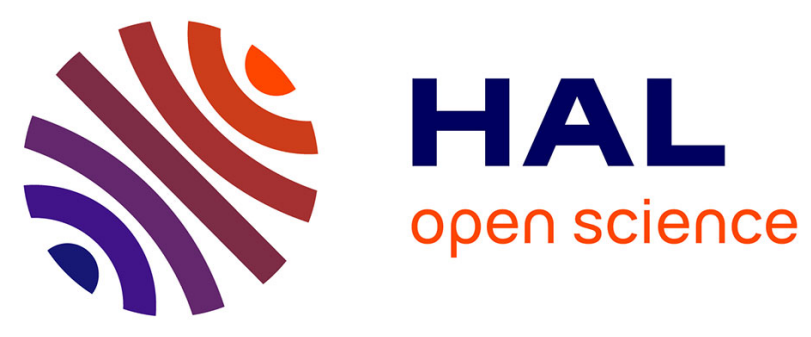

\title{
Azlactone Telechelic Polyolefins as Precursors to Polyamides A Combination of Metathesis Polymerization and Polyaddition Reactions
}

Cyril Chauveau, Elise Vanbiervliet, Stéphane Fouquay, Guillaume Michaud, Frédéric Simon, Jean-Francois Carpentier, Sophie M. Guillaume

\section{To cite this version:}

Cyril Chauveau, Elise Vanbiervliet, Stéphane Fouquay, Guillaume Michaud, Frédéric Simon, et al.. Azlactone Telechelic Polyolefins as Precursors to Polyamides A Combination of Metathesis Polymerization and Polyaddition Reactions. Macromolecules, 2018, 51 (20), pp.8084-8099. 10.1021/acs.macromol.8b01628 . hal-01935366

HAL Id: hal-01935366 https://hal-univ-rennes1.archives-ouvertes.fr/hal-01935366

Submitted on 7 Dec 2018

HAL is a multi-disciplinary open access archive for the deposit and dissemination of scientific research documents, whether they are published or not. The documents may come from teaching and research institutions in France or abroad, or from public or private research centers.
L'archive ouverte pluridisciplinaire $\mathbf{H A L}$, est destinée au dépôt et à la diffusion de documents scientifiques de niveau recherche, publiés ou non, émanant des établissements d'enseignement et de recherche français ou étrangers, des laboratoires publics ou privés. 
Azlactone Telechelic Polyolefins as Precursors to Polyamides: a Combination of Metathesis Polymerization and Polyaddition Reactions

Cyril Chauveau, ${ }^{\mathrm{a}, \dagger}$ Elise Vanbiervliet,,${ }^{\mathrm{a}, \uparrow}$ Stéphane Fouquay, ${ }^{\mathrm{b}}$ Guillaume Michaud, ${ }^{\mathrm{c}}$ Frédéric Simon, ${ }^{c}$ Jean-François Carpentier (ORCID: 0000-0002-9160-7662), ${ }^{\text {a, }}$ and Sophie M. Guillaume (ORCID: 0000-0003-2917-8657) ${ }^{\mathrm{a},{ }^{*}}$

${ }^{a}$ Univ Rennes, CNRS, ISCR (Institut des Sciences Chimiques de Rennes) - UMR 6226, F35000 Rennes, France

${ }^{b}$ BOSTIK S.A., 253, Avenue du Président Wilson, F-93211 La Plaine Saint-Denis, France

${ }^{c}$ BOSTIK, ZAC du Bois de Plaisance, 101, Rue du Champ Cailloux, F-60280 Venette, France

\footnotetext{
${ }^{\dagger}$ Equally contributing authors

*Corresponding authors: jean-francois.carpentier@univ-rennes1; sophie.guillaume@univ-rennes1.fr
} 


\begin{abstract}
Expanding on our strategy to design telechelic polyolefins through the ruthenium-catalyzed ring-opening metathesis polymerization/cross metathesis/ring-closing metathesis polymerization of cyclic olefins using bifunctional symmetric alkene chain transfer agents (CTAs), we have now explored the metathesis of cyclooctene (COE), 1,5,9-cyclododecatriene (CDT), and norbornene (NB), using azlactone (AZL)-functional CTAs, towards the synthesis of original AZL telechelic polyolefins. The monofunctional 2-vinyl-4,4-dimethylazlactone predominantly gives, as anticipated, (isomerized) monofunctional and/or difunctional PCOEs. On the other hand, the new symmetric AZL-based CTAs 1-3, namely, (E)-2,2'-(ethene-1,2diyl)bis(4,4-dimethyloxazol-5(4H)-one) $\quad$ (1), $\quad(E)$-2,2'-(but-2-ene-1,4-diyl)bis(4,4dimethyloxazol-5(4H)-one) (2), (E)-2,2'-(but-2-ene-1,4-diyl)bis(3-oxa-1-azaspiro[4.5]dec-1en-4-one) (3), selectively give $\alpha, \omega$-di(AZL) telechelic PCOEs, along with minor amounts of cyclic PCOE. The synthesis of related AZL telechelic CDT and NB copolymers has also been implemented through such a tandem metathesis approach. Subsequently, the inherent AZL reactivity towards (di)amines has been evidenced using a triethyleneglycol diamine, in first the model reaction with CTA 3, and next upon reacting with the new $\alpha, \omega-\operatorname{di}(\mathrm{CTA} 3)-\mathrm{P}(\mathrm{NB}-$ co-CDT) copolymers, thereby enabling the preparation of original polyolefins/polyamides.
\end{abstract}


Table of contents
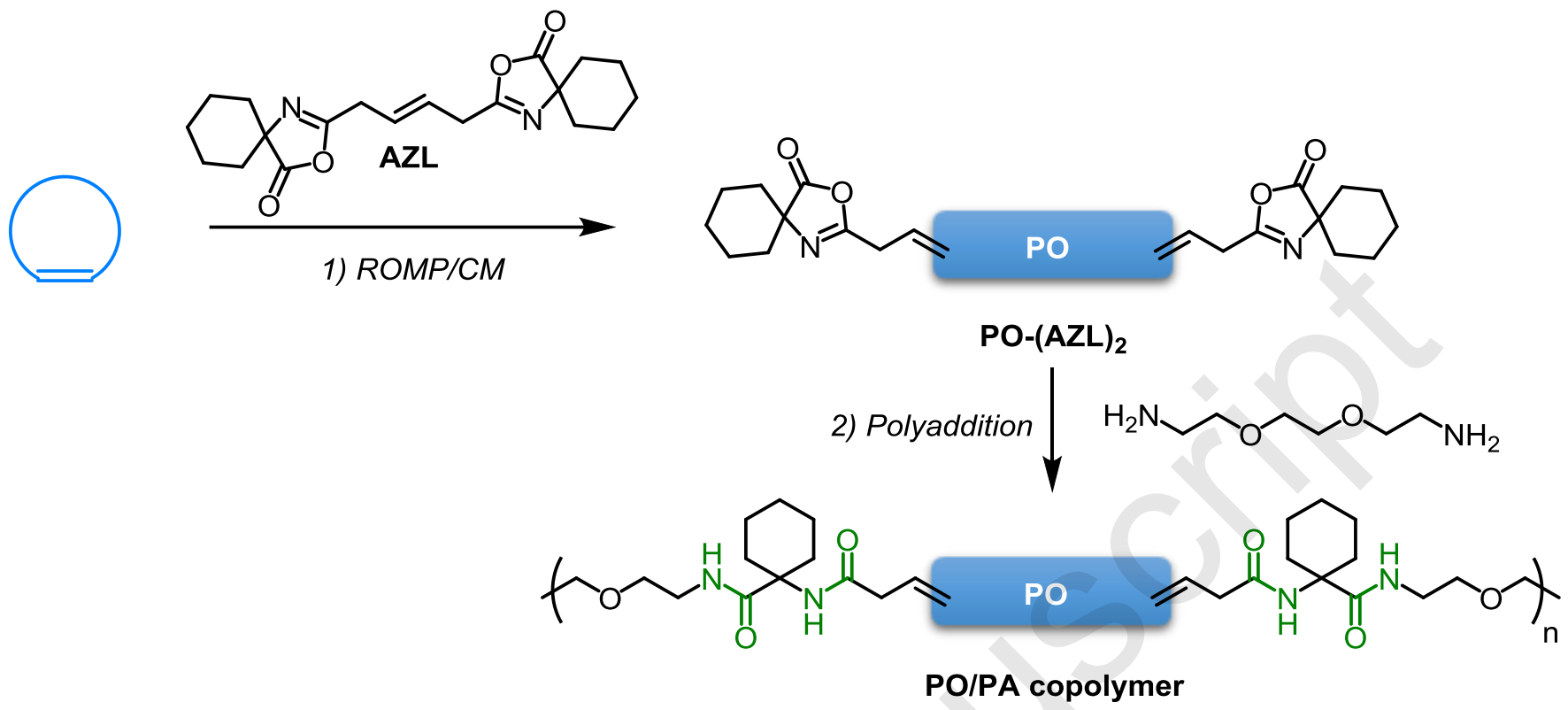


\section{Introduction}

Telechelic polymers, defined as prepolymers capable of entering into further polymerization or other reactions through their reactive end-groups, ${ }^{1}$ are highly valuable synthons. Functional end-groups enable the elaboration of advanced polymeric materials with targeted material properties for end-users applications such as adhesives, coatings, binders, paints, electronics or drug delivery systems. Such end-functional polymeric materials have been considerably developed over the past decades, especially benefiting from living polymerization techniques, allowing the synthesis of well-defined polymers with controlled and tunable characteristics (molar mass and dispersity, chain-end fidelity, functionality, microstructure and tacticity)..$^{2,3,4,5,6}$ In particular, telechelic polyolefins (POs) have gained from advances in functional-group tolerant metathesis polymerizations. ${ }^{7,8,9,10}$ The direct metathesis of cyclic olefins performed in the presence of a bifunctional symmetric alkene chain transfer agent (CTA) enables the direct synthesis of such telechelic POs. CTAs bearing methacrylate ${ }^{11}$ epoxide, ${ }^{11,12}$ carboxylate, ${ }^{13,14,15}$ acetoxy,${ }^{16,17}$, amino, ${ }^{14}$ carbonate, ${ }^{18,19}$ hydroxy, ${ }^{16,17,20,21,22,23,24,25,26,27,28,29}$ halide and pseudo-halide, ${ }^{20}$ cyano, ${ }^{30,31}$ and trialkoxysilyl $^{32,33,34,35}$ functionalities have thus given access to well-defined telechelic POs.

Azlactone (or oxazolone, AZL) functionalized polymers have attracted growing attention over the last two decades as a versatile and modular platform towards the design of reactive materials. Awareness from both industries (especially 3M, Polaroid, Rohm Gmbh) and academic research groups of the potent AZL tool has made such AZL-functional polymer materials to be considered as valuable alternatives to other conventional reactive polymers. AZLs are lactone-based functional imines that undergo rapid ring-opening reactions at room temperature in the presence of nucleophiles such as primary amine, alcohol or thiol (macro)molecules, without requiring the presence of a catalyst and, most commonly, without formation of any byproducts (Scheme S1). Besides ring-opening reactions, cycloaddition, 
alkylation, allylation, arylation, acylation, aldolization, sulfonisation, Michael-, ene- and Mannich-type reactions can also be performed on such platforms, providing a wide range of chemical functions available for post-polymerization modification of AZL-functional polymers. ${ }^{36,37,38,39}$ Other beneficial features of AZL are its relative stability to hydrolysis, enabling its implementation in aqueous processes without significant competitive alteration, and its solubility in common organic solvents thus favoring its reactivity towards a large range of molecules. Incorporation of AZL moieties along the polymer backbone, as pendant functionalities or as chain-end groups, thus provides a wide class of reactive polymers of considerable interest; this is particularly the case in the biological field in which they are used for their high reactivity towards amine residues of proteins or other biological molecules. Several approaches towards AZL-functional polymers involve radical polymerization of 2-vinyl-4,4-dimethylazlactone (VDMA) to form poly(VDMA) with AZL functions further ring-opened by a nucleophile. ${ }^{36,37,38,40,41}$ POs bearing AZL side-groups have been prepared from the ROMP of AZL-functional norbornene using Grubbs' $1^{\text {st }}(\mathbf{G 1})$ or $2^{\text {nd }}(\mathbf{G} 2)$ generation catalyst, thereby demonstrating the compatibility of AZL functions with the metathesis process, and the AZL ring has been subsequently opened by several nucleophiles. ${ }^{42,43}$ Finally, the $3 \mathrm{M}$ company briefly described the use of $\alpha, \omega$-di(AZL) telechelic oligoesters based on VDMA in a curable system for coating and possibly adhesives applications. ${ }^{44}$ However, to our knowledge, the synthesis of $\alpha, \omega$-di(AZL) telechelic polymers and their subsequent use have never been described in the open academic literature.

The room temperature polyaddition of a $\alpha, \omega$-di(AZL) telechelic PO with a diamine should give a $\mathrm{PO} /$ polyamide (PA) material (Scheme 1). PAs represent a predominant class of thermoplastic materials with a wide range of applications due to their high temperature stability, chemical resistance, mechanical strength and low wear and abrasion. The most ubiquitous and largely produced PAs are Nylons - and especially Nylon 6,6 and Nylon 
6. ${ }^{45,46,47}$ Although historically used for textile applications, PAs nowadays found usages in automotive and aerospace fields, electrical, electronic and packaging industry, and in biology and medicine, as coating agents or adhesives amongst others. ${ }^{48,49,50,51,52}$ Combining POs with PAs for the manufacture of hot melt adhesives would enable to benefit from PAs' excellent chemical resistance and high temperature performance, and from POs' low temperature processing (and consequently reduced energy consumption and improved safety) and better adhesion to olefinic substrates, ultimately providing alternatives to high-performing PAs with improved (especially thermomechanical and viscoelastic) properties in demanding assembly applications (adhesives, coatings). To this end, low viscosity liquid polymer materials are desirable.

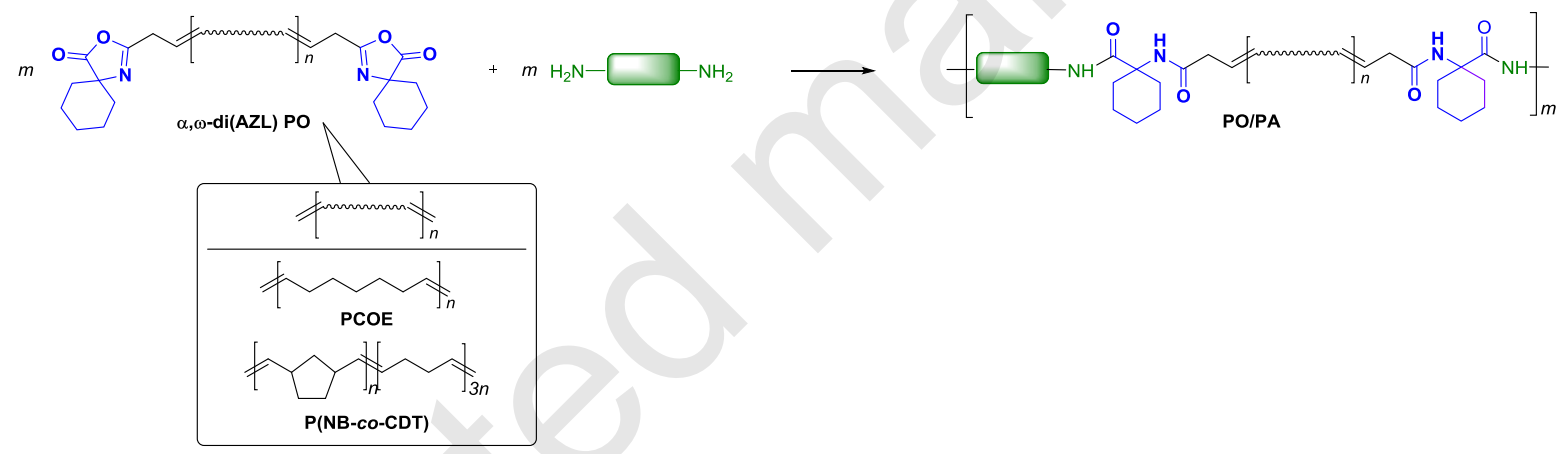

Scheme 1. Polyaddition of an $\alpha, \omega$-di(AZL) telechelic PO with a diamine affording a PO/PA.

The objective of the present work is to establish a strategy to prepare low viscosity, liquid $\alpha, \omega$-di(AZL) telechelic POs and to subsequently prepare PO/PA samples therefrom for possible later adhesive and/or coatings applications. We thus first further expand on our strategy to design telechelic POs through the ring-opening metathesis polymerization (ROMP)/cross metathesis (CM)/ring-closing metathesis (RCM) polymerization of cyclic olefins, in particular cyclooctene (COE), 1,5,9-cyclododecatriene (CDT), and norbornene (NB), using alkene functional CTAs, towards the synthesis of original AZL telechelic POs 
(Scheme 4). ${ }^{12,18,19,32,33,34}$ The tandem ROMP/CM/RCM approach is next extended to the synthesis of AZL telechelic CDT/NB copolymers (Scheme 5). In a second phase, following the prior investigation of the model reaction of CTA 3 with a triethyleneglycol diamine (EDR-148), these $\alpha, \omega$-di(AZL)-P(NB-co-CDT) copolymers are next used for the preparation of PAs thanks to the AZL favorable reactivity towards amines (Schemes 1,6).

\section{Experimental section}

Materials. All catalytic experiments were performed under inert atmosphere (argon, < $3 \mathrm{ppm}$ $\mathrm{O}_{2}$ ) using standard Schlenk line and glove box techniques. Grubbs' $2^{\text {nd }}$ generation catalyst, $\left(\left[\left(\mathrm{IMesH}_{2}\right)\left(\mathrm{Cy}_{3} \mathrm{P}\right) \mathrm{RuCl}_{2}(=\mathrm{CHPh})\right], \quad\right.$ G2),$\quad$ Hoveyda-Grubbs $\quad 2^{\text {nd }}$ generation catalyst $\left(\left[\left(\mathrm{IMesH}_{2}\right)\left(\mathrm{Cy}_{3} \mathrm{P}\right) \mathrm{RuCl}_{2}\left(=\mathrm{CHC}_{6} \mathrm{H}_{4} \mathrm{CMe}_{2} \mathrm{O}\right)\right]\right.$, HG2), fumaroyl chloride, 2-aminoisobutyric acid (TCI), 1-aminocyclohexanecarboxylic acid (TCI), thionyl chloride ( $\mathrm{SOCl}_{2}$, Fisher Scientific), JEFFAMINE EDR-148 (2-[2-(2-aminoethoxy)ethoxy]ethan-1-amine (triethyleneglycol diamine); Huntsman, primary amine content $=13.48$ mequiv.g $\mathrm{g}^{-1}$ ), polyethyleneimine (Lupasol FG®, BASF), (E)-hex-3-enedioic acid, and all other reagents (Aldrich, unless otherwise mentioned), were used as received. Cyclooctene (COE), 1,5,9cyclododecatriene (CDT) and norbornene (NB) were purchased from Sigma-Aldrich or ACROS, and dried and distilled over $\mathrm{CaH}_{2}$ before use. $\mathrm{CH}_{2} \mathrm{Cl}_{2}$ (stabilized with amylene) was purified on a MBraun system over activated $3 \AA$ molecular sieves.

Instrumentation and measurements. ${ }^{1} \mathrm{H}(500,400 \mathrm{MHz})$ and ${ }^{13} \mathrm{C}\left\{{ }^{1} \mathrm{H}\right\}(125,100$ MHz) NMR spectra were recorded on Bruker Avance AM 500 and AM 400 spectrometers at $23{ }^{\circ} \mathrm{C}$ in $\mathrm{CDCl}_{3}, \mathrm{DMSO}-d_{6}$ or THF- $d_{8}$. Chemical shifts $(\delta)$ are reported in ppm and were referenced internally relative to tetramethylsilane $(\delta 0 \mathrm{ppm})$ using the residual ${ }^{1} \mathrm{H}$ and ${ }^{13} \mathrm{C}$ solvent resonances of the deuterated solvent. 
Monomer conversions were determined from ${ }^{1} \mathrm{H}$ NMR spectra of the crude polymer sample, from the integration (Int.) ratio Int.Polymer/[Int.Polymer + Int.monomer], using the methine hydrogens $(-\mathrm{CH} H \mathrm{CH}-: \delta 5.30,5.66$ (PCOE, COE); 5.44, 5.09 (PCDT, CDT); 5.31, 6.04 (PNB, NB).

The molar mass values of the PCOE samples were determined by ${ }^{1} \mathrm{H}$ NMR analysis in $\mathrm{CDCl}_{3}\left(M_{\mathrm{n}, \mathrm{NMR}}\right)$ from the integral value ratio of the signals of end-groups' hydrogens (typically $\delta$ ca. $3.17 \mathrm{ppm}\left(\mathrm{H}^{\mathrm{c}}\right)$ ) to internal olefin hydrogens $\left(\delta\right.$ ca. $\left.5.37\left(\mathrm{H}^{1}\right)\right)($ Figure 1$)$. For copolymers, the molar mass values were determined by ${ }^{1} \mathrm{H}$ NMR analysis according to: $M_{\mathrm{n}, \mathrm{NMR}}=\left\{M_{\mathrm{NB}} \times \operatorname{Int} .\left(\delta \mathrm{H}^{6 \text { trans }} 2.79+\mathrm{H}^{6 \mathrm{cis}} 2.45\right)\right\}+\left\{M_{\mathrm{CDT}} \times \operatorname{Int} .\left(\delta \mathrm{H}^{1,4} 5.41\right) / 3\right\}+M_{\mathrm{CTA} 3}$, with

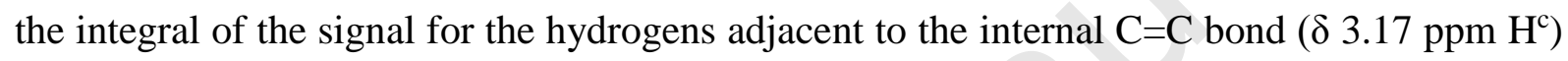
(Figure 4) arbitrarily set to the value of 2.

The average molar mass $\left(M_{\mathrm{n}, \mathrm{SEC}}\right)$ and dispersity $\left(\bigoplus_{\mathrm{M}}=M_{\mathrm{w}} / M_{\mathrm{n}}\right)$ values of the freshly prepared polymer samples (at most within one week unless otherwise stated) were determined by size exclusion chromatography (SEC) in THF at $30{ }^{\circ} \mathrm{C}\left(\right.$ flow rate $=1.0 \mathrm{~mL} \cdot \mathrm{min}^{-1}$ ) on a Polymer Laboratories PL50 apparatus equipped with a refractive index detector and a set of two ResiPore PLgel $3 \mu \mathrm{m}$ MIXED-E $300 \times 7.5 \mathrm{~mm}$ columns. The polymer samples were dissolved in THF $\left(2 \mathrm{mg} \cdot \mathrm{mL}^{-1}\right)$. All elution curves were calibrated with twelve monodisperse polystyrene standards $\left(M_{\mathrm{n}}\right.$ range $\left.=580-380,000 \mathrm{~g} \cdot \mathrm{mol}^{-1}\right) \cdot M_{\mathrm{n}, \mathrm{SEC}}$ values of polymers were uncorrected for their possible difference in hydrodynamic volume in THF vs polystyrene. The SEC traces of the POs all exhibited a monomodal and symmetric peak.

ASAP (Atmospheric Solids Analysis Probe) high-resolution mass spectrometry (HRMS) data were recorded at the CRMPO-Scanmat (Rennes, France) with a Bruker MicrOTOF-Q II mass spectrometer equipped with an APCI (Atmospheric Pressure Chemical Ionisation) source in positive mode by direct introduction at $370{ }^{\circ} \mathrm{C}$. 
ESI (ElectroSpray Ionization) mass spectra were recorded at the CRMPO-Scanmat (Rennes, France) on an orbitrap type Thermo Fisher Scientific Q-Exactive instrument with an ESI source in positive or negative mode by direct introduction at 5-10 $\mu \mathrm{g} / \mathrm{mL}$. Samples were prepared in $\mathrm{CH}_{2} \mathrm{Cl}_{2}$ at $10 \mu \mathrm{g} \cdot \mathrm{mL}^{-1}$.

MALDI-ToF mass spectra of polymers were recorded at the CESAMO (Bordeaux, France) on a Voyager mass spectrometer (Applied Biosystems) equipped with a pulsed $\mathrm{N}_{2}$ laser source ( $337 \mathrm{~nm}, 4 \mathrm{~ns}$ pulse width) and a time-delayed extracted ion source. Spectra were recorded in the positive-ion mode using the reflectron mode and with an accelerating voltage of $20 \mathrm{kV}$. A freshly prepared solution of the polymer sample in THF (HPLC grade, 10 mg. $\left.\mathrm{mL}^{-1}\right)$, a saturated solution of trans-2-[3-(4-tert-butylphenyl)-2-methyl-2-propenylidene]malononitrile (10 mg, DCTB) in THF (1 mL, HPLC grade) were prepared. A MeOH solution of the cationizing agent ( $\mathrm{NaI}$ or AgOTf, $10 \mathrm{mg} \cdot \mathrm{mL}^{-1}$; $\mathrm{Na}^{+}$ions interact with the polymer's heteroatoms enabling the observation of DF PCOE, while $\mathrm{Ag}^{+}$ions interact with all $\mathrm{C}=\mathrm{C}$ containing products enabling the observation of heteroatom-free polymers such as CNF PCOE) was also prepared. The solutions were combined in a 10:1:1 $v / v / v$ of matrix-tosample-to-cationizing agent. The resulting solution (1-2 $\mu \mathrm{L})$ was deposited onto the sample target and vacuum-dried.

FTIR spectra of the polymers were acquired (16 scans) with a resolution of $4 \mathrm{~cm}^{-1}$ on a Shimadzu IRAffinity-1 equipped with an ATR module.

Differential scanning calorimetry (DSC) analyses were performed with a Setaram DSC 131 apparatus calibrated with indium, at a rate of $10{ }^{\circ} \mathrm{Cmin}^{-1}$, under a continuous flow of helium (25 $\mathrm{mL} \cdot \mathrm{min}^{-1}$ ), using aluminum capsules. The thermograms were recorded according to the following cycles: -70 to $120^{\circ} \mathrm{C}$ at $10^{\circ} \mathrm{C} \min ^{-1} ; 120$ to $-70{ }^{\circ} \mathrm{C}$ at $10{ }^{\circ} \mathrm{C}$ $\min ^{-1} ;-70{ }^{\circ} \mathrm{C}$ for $5 \mathrm{~min} ;-70$ to $120{ }^{\circ} \mathrm{C}$ at $10{ }^{\circ} \mathrm{C} \min ^{-1} ; 120$ to $-70{ }^{\circ} \mathrm{C}$ at $10{ }^{\circ} \mathrm{C} \min ^{-1}$. 
Apparent viscosity was measured with an ARES G2 viscosimeter equipped with a plate-plate geometry, at a speed gradient of $0.01 \mathrm{~s}^{-1}$ over a shear rate range from 0.01 to $100 . \mathrm{s}^{-1}$. At each imposed shear rate, the apparent viscosity was determined in the steady state regime. Temperature was fixed at $23 \pm 0.3{ }^{\circ} \mathrm{C}$. For each sample, the viscosimetric test duration was 5 min.

(E)-2,2'-(ethene-1,2-diyl)bis(4,4-dimethyloxazol-5(4H)-one) (1). Fumaroyl chloride (7.73 g, $0.05 \mathrm{~mol}$ ) was added dropwise at $0{ }^{\circ} \mathrm{C}$ to an ice-cooled water solution $(40 \mathrm{~mL})$ of sodium hydroxide $(8.10 \mathrm{~g}, 0.20 \mathrm{~mol})$ and 2-methylalanine (10.90 g, $0.11 \mathrm{~mol})$ (Scheme 2). The reaction mixture was then stirred and allowed to warm to room temperature for $3 \mathrm{~h}$. Aqueous hydrochloric acid (37 wt $\%$ ) was then slowly added to this mixture at $0{ }^{\circ} \mathrm{C}$ to reach $\mathrm{pH}=1-2$, and the resulting solution was stirred for $1 \mathrm{~h}$. After filtration, the recovered white solid was washed with acetone $(100 \mathrm{~mL})$ and dried under vacuum to afford 2,2'-(fumaroylbis(azanediyl))bis(2-methylpropanoic acid) (i) (Scheme 2), as a white powder (10.73 g, 75\%). ${ }^{1} \mathrm{H}$ NMR $\left(500 \mathrm{MHz}, \mathrm{DMSO}-d_{6}, 25^{\circ} \mathrm{C}\right): \delta(\mathrm{ppm}) 1.37 \quad(\mathrm{~s}, \quad 12 \mathrm{H}$, $\left.\mathrm{OHC}(\mathrm{O}) \mathrm{C}\left(\mathrm{CH}_{3}\right)_{2} \mathrm{NHC}(\mathrm{O}) \mathrm{CH}=\right), 6.82\left(\mathrm{~s}, 2 \mathrm{H}, \mathrm{OHC}(\mathrm{O}) \mathrm{C}\left(\mathrm{CH}_{3}\right)_{2} \mathrm{NHC}(\mathrm{O}) \mathrm{CH}=\right), 8.58(\mathrm{~s}, 2 \mathrm{H}$, $\left.\mathrm{OHC}(\mathrm{O}) \mathrm{C}\left(\mathrm{CH}_{3}\right)_{2} \mathrm{NHC}(\mathrm{O}) \mathrm{CH}=\right) .{ }^{13} \mathrm{C}\left\{{ }^{1} \mathrm{H}\right\} \mathrm{NMR}\left(125 \mathrm{MHz}, \mathrm{DMSO}-d_{6}, 25{ }^{\circ} \mathrm{C}\right): \delta(\mathrm{ppm}) 24.5$ $\left(\mathrm{OHC}(\mathrm{O}) \mathrm{C}\left(\mathrm{CH}_{3}\right)_{2} \mathrm{NHC}(\mathrm{O}) \mathrm{CH}=\right), \quad 65.4 \quad\left(\mathrm{OHC}(\mathrm{O}) \mathrm{C}\left(\mathrm{CH}_{3}\right)_{2} \mathrm{NHC}(\mathrm{O}) \mathrm{CH}=\right), \quad 134.2$ $\left(\mathrm{OHC}(\mathrm{O}) \mathrm{C}\left(\mathrm{CH}_{3}\right)_{2} \mathrm{NHC}(\mathrm{O}) \mathrm{CH}=\right), \quad 166.2 \quad\left(\mathrm{OHC}(\mathrm{O}) \mathrm{C}\left(\mathrm{CH}_{3}\right)_{2} \mathrm{NHC}(\mathrm{O}) \mathrm{CH}=\right), \quad 176.2$ $\left(\mathrm{OHC}(\mathrm{O}) \mathrm{C}\left(\mathrm{CH}_{3}\right)_{2} \mathrm{NHC}(\mathrm{O}) \mathrm{CH}=\right)$. HRMS $\quad(\mathrm{ESI}) \quad(\mathrm{m} / \mathrm{z}): \mathrm{C}_{12} \mathrm{H}_{18} \mathrm{~N}_{2} \mathrm{O}_{6} \mathrm{Na} \quad[\mathrm{M}+\mathrm{Na}]^{+}, \quad$ calcd 309.1063, found 309.1060. Next, ethyl chloroformate (0.36 g, $3.40 \mathrm{mmol})$ was added dropwise to a stirring mixture of $\boldsymbol{i}(0.50 \mathrm{~g}, 1.74 \mathrm{mmol})$ and $\mathrm{Et}_{3} \mathrm{~N}(0.44 \mathrm{~g}, 4.30 \mathrm{mmol})$ in DMF $(40 \mathrm{~mL})$ cooled in an ice bath (Scheme 2). The reaction was then allowed to proceed at room temperature for $3 \mathrm{~h}$. The solution was concentrated under vacuum and water $(50 \mathrm{~mL})$ was added. Filtration of the precipitate, and recrystallization from $\mathrm{CH}_{2} \mathrm{Cl}_{2}$ at room temperature afforded white crystals suitable for X-ray diffraction studies (Figure S1). Drying under 
vacuum afforded 1 as a white powder (0.09 g, 20\%, Scheme 2). ${ }^{1} \mathrm{H}$ NMR (400 MHz, $\mathrm{CDCl}_{3}$, $\left.25^{\circ} \mathrm{C}\right): \delta(\mathrm{ppm}) 1.50\left(\mathrm{~s}, 12 \mathrm{H}, \mathrm{OC}(\mathrm{O}) \mathrm{C}\left(\mathrm{CH}_{3}\right)_{2} \mathrm{NCCH}=\right), 6.93\left(\mathrm{~s}, 2 \mathrm{H}, \mathrm{OC}(\mathrm{O}) \mathrm{C}\left(\mathrm{CH}_{3}\right)_{2} \mathrm{NCCH}=\right)$.

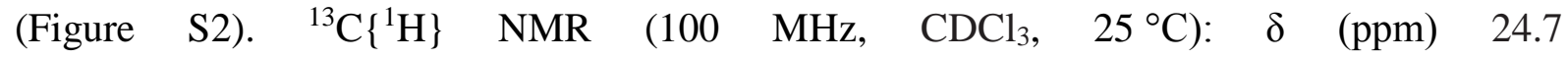
$\left(\mathrm{OC}(\mathrm{O}) \mathrm{C}\left(\mathrm{CH}_{3}\right)_{2} \mathrm{NCCH}=\right), 66.6\left(\mathrm{OC}(\mathrm{O}) \mathrm{C}\left(\mathrm{CH}_{3}\right)_{2} \mathrm{NCCH}=\right), 127.3 \quad\left(\mathrm{OC}(\mathrm{O}) \mathrm{C}\left(\mathrm{CH}_{3}\right)_{2} \mathrm{NCCH}=\right)$, $158.0\left(\mathrm{OC}(\mathrm{O}) \mathrm{C}\left(\mathrm{CH}_{3}\right)_{2} \mathrm{NCCH}=\right), 179.8\left(\mathrm{OC}(\mathrm{O}) \mathrm{C}\left(\mathrm{CH}_{3}\right)_{2} \mathrm{NCCH}=\right)$. (Figure S3). HRMS (ESI) (m/z): $\mathrm{C}_{12} \mathrm{H}_{15} \mathrm{~N}_{2} \mathrm{O}_{4}[\mathrm{M}+\mathrm{H}]^{+}$, calcd 251.10263, found 251.1026. ATR-FTIR ( $\left.\mathrm{cm}^{-1}\right): 3066,1816$, $1639,1284,908$.

(E)-2,2'-(but-2-ene-1,4-diyl)bis(4,4-dimethyloxazol-5(4H)-one) (2). A three-necked flask $(100 \mathrm{~mL})$ equipped with a condenser and magnetic stir bar was charged with trans- $\beta$ hydromuconic acid (7.00 g, $49 \mathrm{mmol})$ and $\mathrm{SOCl}_{2}$ (46.64 g, $392 \mathrm{mmol}$ ) (Scheme 3). The resulting suspension was heated to $75^{\circ} \mathrm{C}$ and stirred over $16 \mathrm{~h}$. Gasses formed during the reaction were trapped with $\mathrm{Et}_{3} \mathrm{~N}$. The resulting clear solution was cooled to room temperature and excess $\mathrm{SOCl}_{2}$ was eliminated under vacuum. The thus recovered $(E)$-hex-3-enedioic dichloride (Scheme 3) was used directly in the next step for the synthesis of $(E)-2,2^{\prime}-(($ hex-3enedioyl)bis(azanediyl))bis(2-methylpropanoic acid) (ii) (73\%, Scheme 3), following a similar approach as described above for the synthesis of 1 (Scheme 1). (E)-hex-3-enedioic dichloride $(7.00 \mathrm{~g}, 65 \mathrm{mmol})$ was added dropwise at $0{ }^{\circ} \mathrm{C}$ to an ice-cooled water solution (40 $\mathrm{mL})$ of sodium hydroxide $(6.73 \mathrm{~g}, 0.17 \mathrm{~mol})$ and 2-methylalanine $(16.70 \mathrm{~g}, 0.16 \mathrm{~mol})$ (Scheme 3). The reaction mixture was then stirred and allowed to warm to room temperature overnight. The reaction mixture was filtrated, and water $(20 \mathrm{~mL})$ was added to the filtrate. Aqueous hydrochloric acid (37 wt $\%$ ) was then slowly added to this mixture at $0{ }^{\circ} \mathrm{C}$ to reach $\mathrm{pH}=1-2$, and the resulting solution was stirred for $1 \mathrm{~h}$. The solution was concentrated and water was removed prior to the addition of a mixture of $\mathrm{CH}_{2} \mathrm{Cl}_{2} /$ methanol $(2: 1 \mathrm{v} / \mathrm{v}, 20 \mathrm{~mL})$. The white solid which thus precipitated was separated by filtration, and washed with acetone $(100 \mathrm{~mL})$ before drying under vacuum to afford (E)-2,2'-((hex-3- 
enedioyl)bis(azanediyl))bis(2-methylpropanoic acid), $\boldsymbol{i i}$, as a white powder (8.17 g, 40\%) (Scheme 3). $\quad{ }^{1} \mathrm{H} \quad \mathrm{NMR} \quad\left(500 \mathrm{MHz}, \quad \mathrm{DMSO}-d_{6}, \quad 25^{\circ} \mathrm{C}\right): \quad \delta \quad(\mathrm{ppm}) \quad 1.31 \quad(\mathrm{~s}, \quad 12 \mathrm{H}$, $\left.\mathrm{OHC}(\mathrm{O}) \mathrm{C}\left(\mathrm{CH}_{3}\right)_{2} \mathrm{NHC}(\mathrm{O}) \mathrm{CH}_{2} \mathrm{CH}=\right), \quad 2.84(\mathrm{~d}, \quad J=4 \mathrm{~Hz}, \quad 4 \mathrm{H}$, $\left.\mathrm{OHC}(\mathrm{O}) \mathrm{C}\left(\mathrm{CH}_{3}\right)_{2} \mathrm{NHC}(\mathrm{O}) \mathrm{CH}_{2} \mathrm{CH}=\right), 5.52\left(\mathrm{~m}, 2 \mathrm{H}, \mathrm{OHC}(\mathrm{O}) \mathrm{C}\left(\mathrm{CH}_{3}\right)_{2} \mathrm{NHC}(\mathrm{O}) \mathrm{CH}_{2} \mathrm{CH}=\right), 8.04$ (s, 2H, OHC(O)C(CH$\left.)_{2} \mathrm{NHC}(\mathrm{O}) \mathrm{CH}_{2} \mathrm{CH}=\right) .{ }^{13} \mathrm{C}\left\{{ }^{1} \mathrm{H}\right\}$ NMR $\left(125 \mathrm{MHz}, \mathrm{DMSO}-d_{6}, 25^{\circ} \mathrm{C}\right): \delta$ (ppm) $24.2\left(\mathrm{OHC}(\mathrm{O}) \mathrm{C}\left(\mathrm{CH}_{3}\right)_{2} \mathrm{NHC}(\mathrm{O}) \mathrm{CH}_{2} \mathrm{CH}=\right), 39.4\left(\mathrm{OHC}(\mathrm{O}) \mathrm{C}\left(\mathrm{CH}_{3}\right)_{2} \mathrm{NHC}(\mathrm{O}) \mathrm{CH}_{2} \mathrm{CH}=\right)$, $65.4\left(\mathrm{OHC}(\mathrm{O}) \mathrm{C}\left(\mathrm{CH}_{3}\right)_{2} \mathrm{NHC}(\mathrm{O}) \mathrm{CH}_{2} \mathrm{CH}=\right), 129.2\left(\mathrm{OHC}(\mathrm{O}) \mathrm{C}\left(\mathrm{CH}_{3}\right)_{2} \mathrm{NHC}(\mathrm{O}) \mathrm{CH}_{2} \mathrm{CH}=\right), 166.2$ $\left(\mathrm{OHC}(\mathrm{O}) \mathrm{C}\left(\mathrm{CH}_{3}\right)_{2} \mathrm{NHC}(\mathrm{O}) \mathrm{CH}_{2} \mathrm{CH}=\right), \quad 176.2 \quad\left(\mathrm{OHC}(\mathrm{O}) \mathrm{C}\left(\mathrm{CH}_{3}\right)_{2} \mathrm{NHC}(\mathrm{O}) \mathrm{CH}_{2} \mathrm{CH}=\right) . \quad \mathrm{HRMS}$ (ESI) $(m / z): \mathrm{C}_{14} \mathrm{H}_{21} \mathrm{~N}_{2} \mathrm{O}_{6}[\mathrm{M}-\mathrm{H}]^{-}$, calcd 313.1405, found 313.1404. To a stirred mixture of $\boldsymbol{i i}$ $(4.12 \mathrm{~g}, 0.013 \mathrm{~mol})$ heated in an oil bath at $120{ }^{\circ} \mathrm{C}$, acetic anhydride $(10.71 \mathrm{~g}, 0.105 \mathrm{~mol})$ was added (Scheme 3). The reaction flask was removed from the oil bath after $10 \mathrm{~min}$ and the solution was concentrated under vacuum. The resulting solid was filtrated and dissolved in methanol $(10 \mathrm{~mL})$ to give a yellowish precipitate, which was next recrystallized from acetone. Ultimate drying of the solid gave 2 as a white powder $(0.72 \mathrm{~g}, 20 \%) .{ }^{1} \mathrm{H}$ NMR (400 MHz, DMSO- $\left.d_{6}, 25^{\circ} \mathrm{C}\right): \delta(\mathrm{ppm}) 1.33\left(\mathrm{~s}, 12 \mathrm{H}, \mathrm{OC}(\mathrm{O}) \mathrm{C}\left(\mathrm{CH}_{3}\right)_{2} \mathrm{NCCH}_{2} \mathrm{CH}=\right), 3.31(\mathrm{~m}, 4 \mathrm{H}$, $\left.\mathrm{OC}(\mathrm{O}) \mathrm{C}\left(\mathrm{CH}_{3}\right)_{2} \mathrm{NCCH}_{2} \mathrm{CH}=\right), 5.77\left(\mathrm{~m}, 2 \mathrm{H}, \mathrm{OC}(\mathrm{O}) \mathrm{C}\left(\mathrm{CH}_{3}\right)_{2} \mathrm{NCCH}_{2} \mathrm{CH}=\right.$ ) (Figure $\left.\mathrm{S} 4\right) .{ }^{13} \mathrm{C}\left\{{ }^{1} \mathrm{H}\right\}$ NMR (100 MHz, DMSO- $\left.d_{6}, 25^{\circ} \mathrm{C}\right): \delta(\mathrm{ppm}) 24.5\left(\mathrm{OC}(\mathrm{O}) \mathrm{C}\left(\mathrm{CH}_{3}\right)_{2} \mathrm{NCCH}_{2} \mathrm{CH}=\right), 31.8$ $\left(\mathrm{OC}(\mathrm{O}) \mathrm{C}\left(\mathrm{CH}_{3}\right)_{2} \mathrm{NCCH}_{2} \mathrm{CH}=\right), \quad 65.4 \quad\left(\mathrm{OC}(\mathrm{O}) \mathrm{C}\left(\mathrm{CH}_{3}\right)_{2} \mathrm{NCCH}_{2} \mathrm{CH}=\right), \quad 126.2$ $\left(\mathrm{OC}(\mathrm{O}) \mathrm{C}\left(\mathrm{CH}_{3}\right)_{2} \mathrm{NCCH}_{2} \mathrm{CH}=\right), \quad 161.2 \quad\left(\mathrm{OC}(\mathrm{O}) \mathrm{C}\left(\mathrm{CH}_{3}\right)_{2} \mathrm{NCCH}_{2} \mathrm{CH}=\right), \quad 181.8$ $\left(\mathrm{OC}(\mathrm{O}) \mathrm{C}\left(\mathrm{CH}_{3}\right)_{2} \mathrm{NCCH}_{2} \mathrm{CH}=\right.$ ) (Figure S5). HRMS (ESI) $(\mathrm{m} / \mathrm{z}): \mathrm{C}_{14} \mathrm{H}_{18} \mathrm{~N}_{2} \mathrm{O}_{4} \mathrm{Na} \quad[\mathrm{M}+\mathrm{Na}]^{+}$, calcd 301.1164, found 301.1167. ATR-FTIR $\left(\mathrm{cm}^{-1}\right)$ : 1813, 1678, 1209, 1159, 1070, 964, 893. (E)-2,2'-(but-2-ene-1,4-diyl)bis(3-oxa-1-azaspiro[4.5]dec-1-en-4-one) (3). The recovered (E)-hex-3-enedioic dichloride synthesized as described above (Scheme 3) was used directly in the next step for the synthesis of (E)-1,1'-((hex-3enedioyl)bis(azanediyl))dicyclohexanecarboxylic diacid (iii; Scheme 3). (E)-hex-3-enedioic 
dichloride $(5.78 \mathrm{~g}, 32 \mathrm{mmol})$ was added dropwise at $0{ }^{\circ} \mathrm{C}$ to an ice-cooled water solution (100 $\mathrm{mL})$ of $\mathrm{NaOH}(3.14 \mathrm{~g}, 86 \mathrm{mmol})$ and 1-aminocyclohexanecarboxylic acid (10.0 g, $70 \mathrm{~mol})$ (Scheme 3). The reaction mixture was stirred and allowed to warm to room temperature overnight. Aqueous hydrochloric acid (37 wt $\%$ ) was slowly added to this mixture at $0{ }^{\circ} \mathrm{C}$ to reach $\mathrm{pH}=1-2$, and the resulting solution was stirred for $1 \mathrm{~h}$. The reaction mixture was filtrated, and the white solid thus obtained was washed with acetone $(100 \mathrm{~mL})$ before drying under vacuum to afford (E)-1,1'-((hex-3-enedioyl)bis(azanediyl))dicyclohexanecarboxylic diacid iii as a white powder (5.40 g, 43\%) (Scheme 3). ${ }^{1} \mathrm{H}$ NMR (500 MHz, DMSO-d6, $\left.25^{\circ} \mathrm{C}\right): \delta(\mathrm{ppm}) 1.12-1.93\left(\mathrm{~m}, 20 \mathrm{H}, \mathrm{OHC}(\mathrm{O}) \mathrm{C}\left(\mathrm{C}_{5} \mathrm{H}_{10}\right) \mathrm{NHC}(\mathrm{O}) \mathrm{CH}_{2} \mathrm{CH}=\right), 2.89(\mathrm{~d}, J=4 \mathrm{~Hz}$, $\left.4 \mathrm{H}, \mathrm{OHC}(\mathrm{O}) \mathrm{C}\left(\mathrm{C}_{5} \mathrm{H}_{10}\right) \mathrm{NHC}(\mathrm{O}) \mathrm{CH}_{2} \mathrm{CH}=\right), 5.57\left(\mathrm{~m}, 2 \mathrm{H}, \mathrm{OHC}(\mathrm{O}) \mathrm{C}\left(\mathrm{C}_{5} \mathrm{H}_{10}\right) \mathrm{NHC}(\mathrm{O}) \mathrm{CH}_{2} \mathrm{CH}=\right)$, $7.74 \quad\left(\mathrm{~s}, \quad 2 \mathrm{H}, \quad \mathrm{OHC}(\mathrm{O}) \mathrm{C}\left(\mathrm{C}_{5} \mathrm{H}_{10}\right) \mathrm{NHC}(\mathrm{O}) \mathrm{CH}_{2} \mathrm{CH}=\right), \quad 12.0 \quad(\mathrm{~m}, \quad 2 \mathrm{H}$, $\left.H \mathrm{OC}(\mathrm{O}) \mathrm{C}\left(\mathrm{C}_{5} \mathrm{H}_{10}\right) \mathrm{NHC}(\mathrm{O}) \mathrm{CH}_{2} \mathrm{CH}=\right) .{ }^{13} \mathrm{C}\left\{{ }^{1} \mathrm{H}\right\} \mathrm{NMR}\left(125 \mathrm{MHz}, \mathrm{DMSO}-d_{6}, 25{ }^{\circ} \mathrm{C}\right): \delta(\mathrm{ppm})$ 21.2-32.4 ( $\left.\mathrm{OHC}(\mathrm{O}) \mathrm{C}\left(C_{5} \mathrm{H}_{10}\right) \mathrm{NHC}(\mathrm{O}) \mathrm{CH}_{2} \mathrm{CH}=\right), 39.5\left(\mathrm{OHC}(\mathrm{O}) \mathrm{C}\left(\mathrm{C}_{5} \mathrm{H}_{10}\right) \mathrm{NHC}(\mathrm{O}) \mathrm{CH}_{2} \mathrm{CH}=\right)$, $62.4\left(\mathrm{OHC}(\mathrm{O}) \mathrm{C}\left(\mathrm{C}_{5} \mathrm{H}_{10}\right) \mathrm{NHC}(\mathrm{O}) \mathrm{CH}_{2} \mathrm{CH}=\right), \quad 129.1 \quad\left(\mathrm{OHC}(\mathrm{O}) \mathrm{C}\left(\mathrm{C}_{5} \mathrm{H}_{10}\right) \mathrm{NHC}(\mathrm{O}) \mathrm{CH}_{2} \mathrm{CH}=\right)$, $166.4\left(\mathrm{OHC}(\mathrm{O}) \mathrm{C}\left(\mathrm{C}_{5} \mathrm{H}_{10}\right) \mathrm{NHC}(\mathrm{O}) \mathrm{CH}_{2} \mathrm{CH}=\right), 176.5\left(\mathrm{OHC}(\mathrm{O}) \mathrm{C}\left(\mathrm{C}_{5} \mathrm{H}_{10}\right) \mathrm{NHC}(\mathrm{O}) \mathrm{CH}_{2} \mathrm{CH}=\right) . \mathrm{A}$ stirred mixture of $\boldsymbol{i i i}(5.40 \mathrm{~g}, 13.6 \mathrm{mmol})$ and acetic anhydride (11.1 g, $109 \mathrm{mmol})$ was heated in an oil bath at $120^{\circ} \mathrm{C}$ until complete dissolution of iii. The reaction flask was removed from the oil bath and immediately cooled to $0{ }^{\circ} \mathrm{C}$. The mixture was then left at RT for 1 day and at $-40{ }^{\circ} \mathrm{C}$ for 3 days to allow the growth of yellowish crystals. The solution was filtrated and the recovered material was recrystallized twice from acetone. Ultimate drying of the solid gave CTA 3 as white crystals $(0.94 \mathrm{~g}, 19 \%) .{ }^{1} \mathrm{H}$ NMR (400 MHz, DMSO- $\left.d_{6}, 25{ }^{\circ} \mathrm{C}\right): \delta(\mathrm{ppm})$ 1.42-1.62 (m, 20H, $\left.\quad \mathrm{OC}(\mathrm{O}) \mathrm{C}\left(\mathrm{C}_{5} \mathrm{H}_{10}\right) \mathrm{NCCH}_{2} \mathrm{CH}=\right), \quad 3.33 \quad(\mathrm{~m}, \quad 4 \mathrm{H}$, $\left.\mathrm{OC}(\mathrm{O}) \mathrm{C}\left(\mathrm{C}_{5} \mathrm{H}_{10}\right) \mathrm{NCCH}_{2} \mathrm{CH}=\right), \quad 5.79 \quad\left(\mathrm{~m}, \quad 2 \mathrm{H}, \quad \mathrm{OC}(\mathrm{O}) \mathrm{C}\left(\mathrm{C}_{5} \mathrm{H}_{10}\right) \mathrm{NCCH}_{2} \mathrm{CH}=\right) \quad$ (Figure S6). ${ }^{13} \mathrm{C}\left\{{ }^{1} \mathrm{H}\right\} \quad \mathrm{NMR} \quad\left(100 \mathrm{MHz}, \quad \mathrm{DMSO}-d_{6}, \quad 25^{\circ} \mathrm{C}\right): \quad \delta \quad(\mathrm{ppm}) \quad 20.7, \quad 24.4, \quad 32.9$ $\left(\mathrm{OC}(\mathrm{O}) \mathrm{C}\left(C_{5} \mathrm{H} 10\right) \mathrm{NCCH}_{2} \mathrm{CH}=\right), \quad 31.3 \quad\left(\mathrm{OC}(\mathrm{O}) \mathrm{C}\left(\mathrm{C}_{5} \mathrm{H}_{10}\right) \mathrm{NCCH}_{2} \mathrm{CH}=\right), \quad 67.5$ 
$\left(\mathrm{OC}(\mathrm{O}) \mathrm{C}\left(\mathrm{C}_{5} \mathrm{H}_{10}\right) \mathrm{NCCH}_{2} \mathrm{CH}=\right)$

$\left(\mathrm{OC}(\mathrm{O}) \mathrm{C}\left(\mathrm{C}_{5} \mathrm{H}_{10}\right) \mathrm{NCCH}_{2} \mathrm{CH}=\right), 180.7\left(\mathrm{OC}(\mathrm{O}) \mathrm{C}\left(\mathrm{C}_{5} \mathrm{H}_{10}\right) \mathrm{NCCH}_{2} \mathrm{CH}=\right)$ (Figure S7). HRMS (ESI) $(\mathrm{m} / \mathrm{z}): \mathrm{C}_{20} \mathrm{H}_{26} \mathrm{~N}_{2} \mathrm{O}_{4} \mathrm{Na}[\mathrm{M}+\mathrm{Na}]^{+}$, calcd 381.1790, found 381.1788. ATR-FTIR $\left(\mathrm{cm}^{-1}\right)$ : 3066, 1816, 1639, 1284, 908. Crystallization of CTA 3 from acetone afforded white crystals suitable for X-ray diffraction studies (Figure S8).

General procedure for the polymerization of COE. All polymerizations were performed according to the following typical procedure (Table 1, entry 2). The only differences lie in the nature of the solvent, CTA and its initial concentration ([CTA $\left.]_{0}\right)$. Under argon atmosphere, a Schlenk flask equipped with a magnetic stir bar, was charged sequentially with dry $\mathrm{CH}_{2} \mathrm{Cl}_{2}$ (5.0 mL), COE (1.53 mL, $1.29 \mathrm{~g}, 11.7 \mathrm{mmol})$ and CTA $1(27 \mathrm{mg}, 0.12 \mathrm{mmol})$. The initial concentration of COE was kept at 1.8 mol. $\mathrm{L}^{-1}$. The resulting solution was heated at $40{ }^{\circ} \mathrm{C}$ and the polymerization was started upon addition, via a cannula, of a freshly prepared $\mathrm{CH}_{2} \mathrm{Cl}_{2}$ solution $(2.0 \mathrm{~mL})$ of $\mathbf{G 2}(5.0 \mathrm{mg}, 5.9 \mu \mathrm{mol})$. The reaction mixture turned highly viscous within $2 \mathrm{~min}$. The viscosity then slowly decreased over the following $10 \mathrm{~min}$. After the desired reaction time (typically $24 \mathrm{~h}$; reaction time was not necessarily optimized), volatiles (solvent and ethylene) were removed under vacuum. The polymer was recovered upon precipitation in methanol $(50 \mathrm{~mL})$ (thereby allowing removal of the catalyst), filtration and drying at $25^{\circ} \mathrm{C}$ under vacuum. All polymers were recovered as white powders, which are readily soluble in $\mathrm{CHCl}_{3}$ and $\mathrm{THF}$, and insoluble in $\mathrm{MeOH}$ (Tables 1,S1). All experiments were at least duplicated. The isolated polymers were characterized by ${ }^{1} \mathrm{H},{ }^{13} \mathrm{C}\left\{{ }^{1} \mathrm{H}\right\} \mathrm{NMR}$ spectroscopy, MALDI-ToF MS and DSC analyses (Figures 1-3, S9-S16).

General procedure for the copolymerization of NB and CDT. Typically, under an argon atmosphere, a Schlenk flask equipped with a magnetic stir bar was charged sequentially with $\left(\mathrm{CH}_{2} \mathrm{Cl}\right)_{2}(10.0 \mathrm{~mL}), \mathrm{NB}(0.66 \mathrm{~g}, 7.01 \mathrm{mmol}), \mathrm{CDT}(1.40 \mathrm{~mL}, 1.13 \mathrm{~g}, 7.01 \mathrm{mmol})$ and CTA 3 (100 mg, $0.28 \mathrm{mmol}$ ) (Table 2, entry 2). The resulting solution was heated at $60{ }^{\circ} \mathrm{C}$ and the 
polymerization was started upon addition, via a cannula, of a dry, freshly prepared $\mathrm{CH}_{2} \mathrm{Cl}_{2}$ solution $(4.0 \mathrm{~mL})$ of $\mathbf{G} 2(3.0 \mathrm{mg}, 3.5 \mu \mathrm{mol})$. Note that reactions carried out in $\mathrm{CH}_{2} \mathrm{Cl}_{2}$ or THF were run at $40{ }^{\circ} \mathrm{C}$ or $60{ }^{\circ} \mathrm{C}$, respectively. The reaction mixture turned highly viscous within 2 min. The viscosity then visually slowly decreased over the following $10 \mathrm{~min}$. After the desired reaction time (typically $24 \mathrm{~h}$; reaction time was not necessarily optimized), volatiles (solvent and ethylene) were removed under vacuum. The copolymer was recovered without further purification, as a brownish viscous liquid at $25^{\circ} \mathrm{C}$, which is readily soluble in $\mathrm{CHCl}_{3}$ and THF, and insoluble in $\mathrm{MeOH}$ (Tables 2-3). The isolated copolymers were characterized by ${ }^{1} \mathrm{H},{ }^{13} \mathrm{C}\left\{{ }^{1} \mathrm{H}\right\}$ NMR spectroscopy, DSC and viscosimetric analyses (Figures 4, S17-S19).

Quantification of cyclic non-functional (CNF) copolymers in the crude copolymers. CNF copolyolefins were separated from the crude $\alpha, \omega$-di(AZL)P(NB-co-CDT) copolymers by eluting a mixture issued from the reaction of the crude copolymers with a multifunctional amine (Lupasol $\mathrm{FG}{ }^{\circledR}$ ) (1.5 equiv $\mathrm{NH}_{2}$ vs $\left.\mathrm{AZL}\right)$ in $\mathrm{CH}_{2} \mathrm{Cl}_{2}(50 \mathrm{~mL})$, through a column chromatography on silica, using pentane as eluent. The AZL end-groups of the copolymers which react with the amine functions to form the PA, thus enabled the copolymers (DF) to remain grafted onto the silica, while CNF copolymers (apolar and without significant interaction with silica) were isolated from the eluted solution. The CNF materials were then weighted and characterized by ${ }^{1} \mathrm{H}$ NMR and SEC (Table 2).

Determination of the AZL content in the (co)polymers. The AZL content of the (co)polymers was determined with 4-bromobenzonitrile as internal NMR standard, using the characteristic resonances of 4-bromobenzonitrile $\left(\delta(\mathrm{ppm}) 7.75,7.69\left(\mathrm{H}^{\alpha}, \mathrm{H}^{\beta}\right)\right)$ and of AZL $(\delta$ (ppm) 3.17-3.25 ( $\left.\left.\mathrm{H}^{\mathrm{c}}\right)\right)$.

General procedure for the polyaddition between a telechelic $\alpha, \omega$-di(AZL) CTA or prepolymer and a diamine. All syntheses of PAs were performed according to the following typical procedure. In a glass vial, the $\alpha, \omega$-di(AZL) telechelic $\mathrm{P}(\mathrm{NB}-\mathrm{co}-\mathrm{CDT})$ copolymer (108 
$\mathrm{mg}, 0.82 \mathrm{mmol}(\mathrm{AZL}) \cdot \mathrm{g}^{-1}$, as determined above) was solubilized in dry $\mathrm{CH}_{2} \mathrm{CL}_{2}(1.0 \mathrm{~mL})$ solution of poly(etherdiamine) (JEFFAMINE EDR-148) (6.6 mg.mL ${ }^{-1}, 0.089$ mmol, 13.5 $\operatorname{mmol}\left(\mathrm{NH}_{2}\right) \cdot \mathrm{g}^{-1}$ ) at $40{ }^{\circ} \mathrm{C}$ (to improve the solubility of the copolymer) under argon. Precipitation was observed to occur typically after $2 \mathrm{~h}$. After $24 \mathrm{~h}$, volatiles were distilled out and the resulting polymer was dried under vacuum. A brownish elastic material, insoluble in common organic solvents after drying, sticky (to the glass wall) and stretchable with shape recovery, was then isolated (Table 3, entry 5). The polymers were characterized by NMR (when soluble), ATR-FTIR, TGA, and DSC analyses (Figures 5-8, S20-S32).

\section{Results and Discussion}

Synthesis of diazlactone functional CTAs. Unsaturated azlactone type compounds are generally derived from natural or synthetic amino acids, upon cycloaddition of the activated acid (most frequently by ethyl chloroformate, ${ }^{53}$ or by acetic anhydride, ${ }^{54} N, N^{\prime}$ dicyclohexylcarbodiimide (DCC), ${ }^{55}$ or upon substituting the acid function by an ethyl or methyl ester function), ${ }^{56}$ as reported for the synthesis of the most common unsaturated azlactone, namely VDMA (Scheme S2)..$^{53,57,58}$

(E)-2,2'-(Ethene-1,2-diyl)bis(4,4-dimethyloxazol-5(4H)-one) (1) was synthesized following this same approach after optimization of the procedure. ${ }^{53,57,58}$ The reaction of fumaroyl chloride with an excess of 2-methylalanine led to intermediate $(i)$, of which the two acidic functions then reacted with ethyl chloroformate and $\mathrm{NEt}_{3}$ to afford the new diazlactone compound 1 (Scheme 2). 


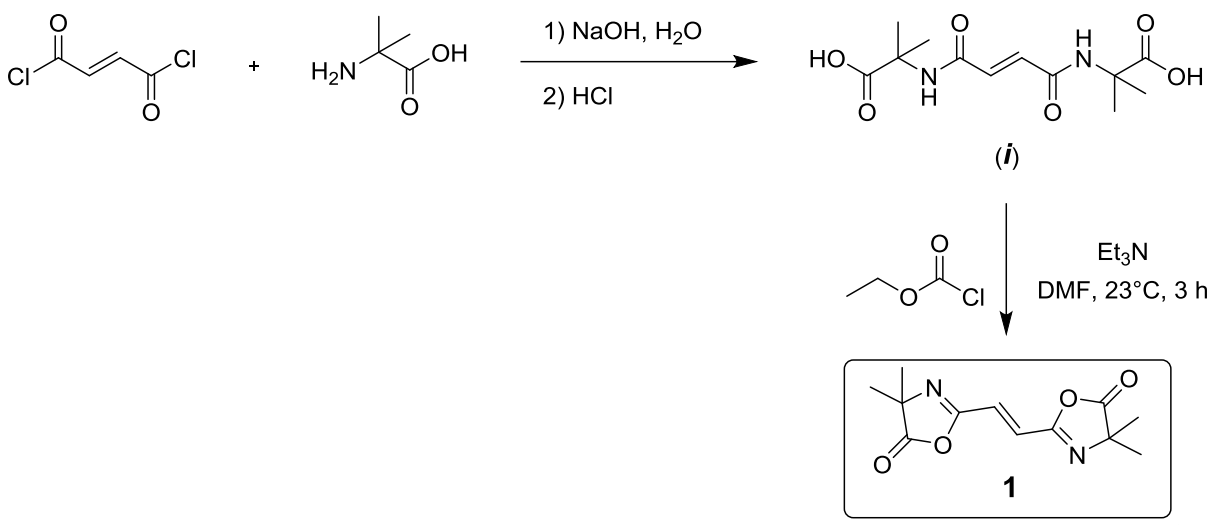

Scheme 2. Synthesis of CTA 1.

The other two AZL difunctional CTAs, (E)-2,2'-(but-2-ene-1,4-diyl)bis(4,4dimethyloxazol-5(4H)-one) (2) and (E)-2,2'-(but-2-ene-1,4-diyl)bis(3-oxa-1-azaspiro[4.5]dec1-en-4-one) (3), featuring as compared to CTA $\mathbf{1}$ an additional methylene between the $\mathrm{C}=\mathrm{C}$ double bond and the AZL function, were next targeted in order to evaluate the impact of the delocalization of $\mathrm{C}=\mathrm{C}$ electrons on the ROMP/CM/RCM of COE. The cyclohexyl moiety in $\mathbf{3}$ was introduced to provide better solubility to the CTA and resulting $\alpha, \omega$-AZL-difunctional POs. Reaction of 2-methylalanine or 1-aminocyclohexane-carboxylic acid with (E)-hex-3-ene dioyl dichloride gave compounds $\boldsymbol{i i}$ or $\boldsymbol{i i i}$, respectively (Scheme 3). The latter diacids were next reacted with acetic anhydride to afford the original symmetric AZL alkene CTAs 2 and 3, respectively.

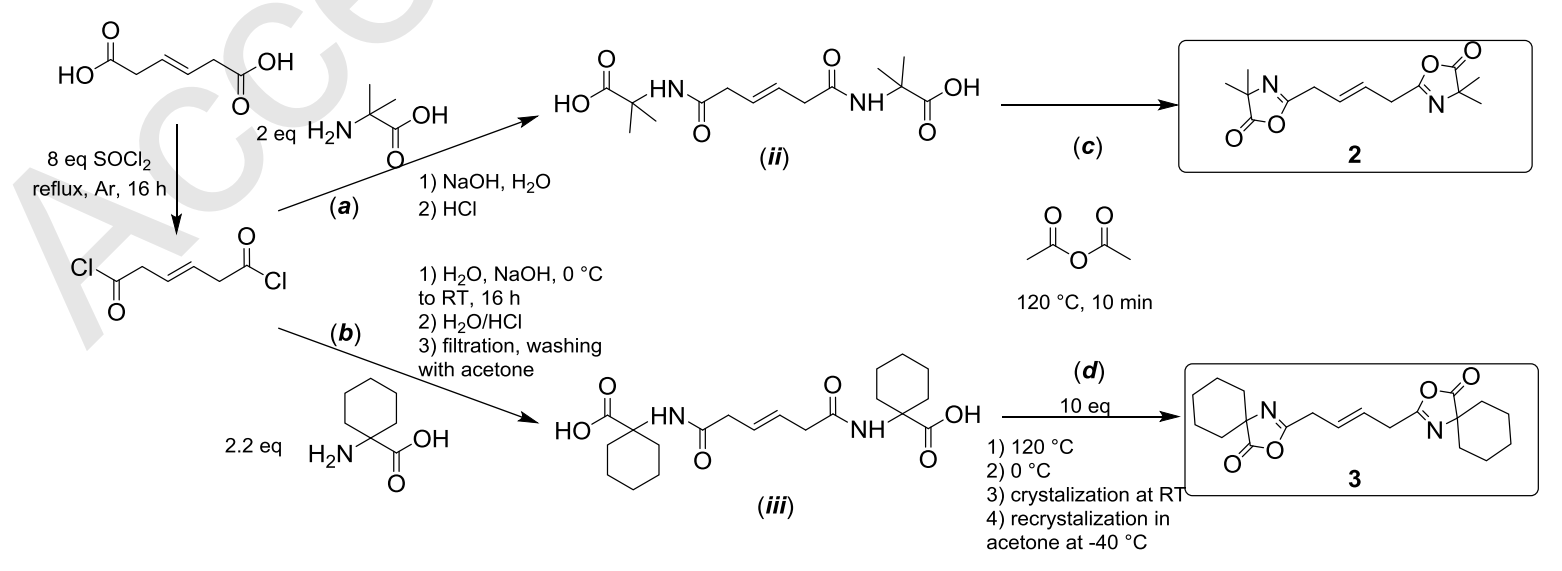

Scheme 3. Synthesis of CTAs 2 and $\mathbf{3 .}$ 
Azlactone telechelic (co)polyolefins. The tandem ROMP/CM/RCM of COE, CDT and NB, catalyzed by $\mathbf{G 2}$, in the presence of several azlactone-based alkene CTAs, including both monofunctional (VDMA), or difunctional $(\mathbf{1}, \mathbf{2}$, and 3) CTAs, was investigated towards the synthesis of $\alpha, \omega$-diazlactone telechelic PCOEs (Scheme 4) and P(NB-co-CDT)s (Scheme 5), the later ultimately serving as precursors to PAs (Schemes 1 and 6).

Azlactone telechelic polyolefins: ROMP of COE catalyzed by G2 in the presence of CTAs VDMA, 1, 2 or 3. The use of the asymmetric monofunctional CTA VDMA in the ROMP of COE catalyzed by G2, was expected to result, as previously reported, in a statistical distribution of AZL end-capped PCOEs, including linear (possibly isomerized) and/or cyclic non-functional (LNF, ILNF, CNF, respectively) polymers, and (possibly isomerized) $\alpha$-monofunctional (IMF, MF) and/or $\alpha, \omega$-difunctional (DF) PCOEs (Scheme S3). ${ }^{12,32,33}$ The ROMP/CM/RCM proceeded overall with a good control of the PCOE molar mass and dispersity values (Table S1); yet, the observed formation of isomerized PCOE (IMF and possibly ILNF) as well as of other PCOEs (MF and/or DF, LNF, CNF) along with some CTA $\mathbf{1}$ arising from the self-metathesis of VDMA (Figure S9), prompted us to favor the use of symmetric alkene CTAs 1, 2, and 3 towards the targeted $\alpha, \omega$-AZL-difunctional POs.

Use of symmetric CTAs such as di(AZL) CTAs 1-3, enabled, under similar operating conditions (G2 catalyst, 40 or $60^{\circ} \mathrm{C}$ for $24 \mathrm{~h}$ ), the selective formation of $\alpha, \omega$-difunctional (DF) PCOEs, possibly along with minor amounts of cyclic polymers (CNF; Scheme 4). This observation highlighted, as anticipated, ${ }^{12,32-34}$ that the functionality of PCOEs is predominantly imparted by the nature of the CTA, as well as, to a lesser extent, by the operating conditions. The most representative results are summarized in Table 1. 


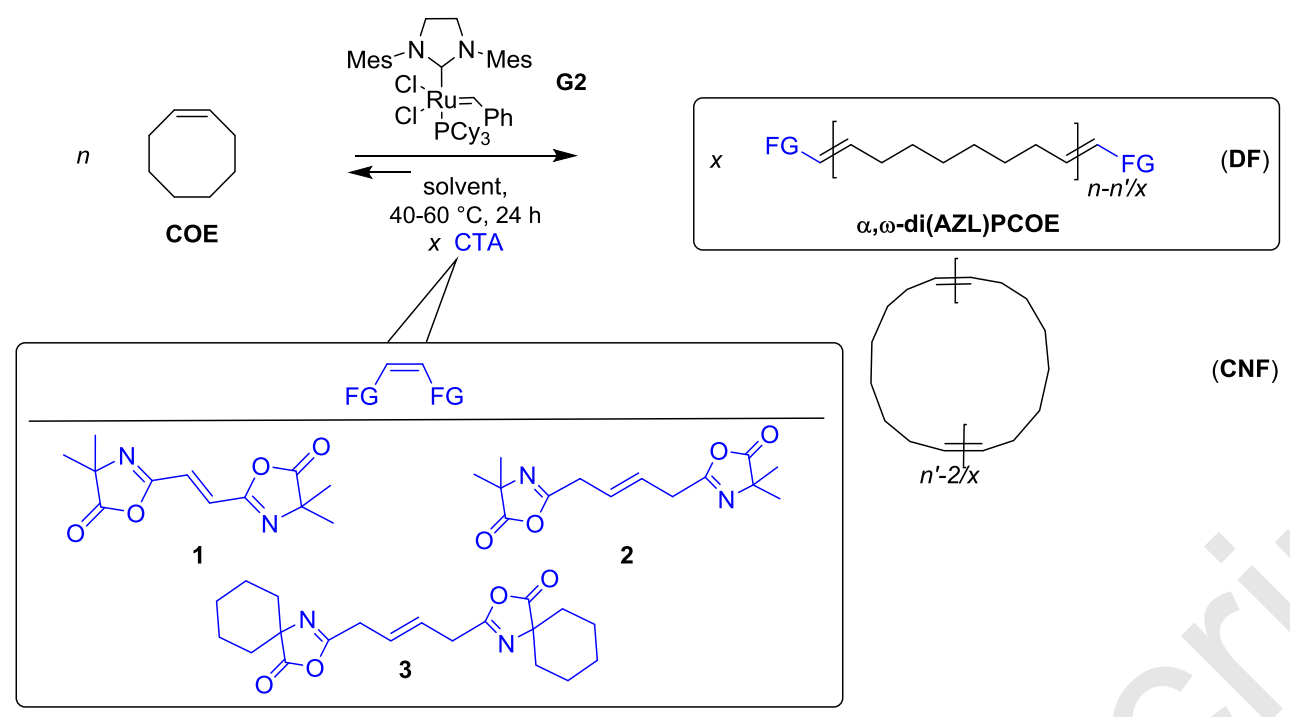

Scheme 4. Tandem ROMP/CM/RCM of COE catalyzed by $\mathbf{G 2}$ in the presence of a difunctional AZL alkene CTAs 1, 2, or 3, showing the possible PCOEs (FG: AZL functional group; DF: $\alpha, \omega$-difunctional, CNF: cyclic non-functional). 
Table 1. Tandem ROMP/CM/RCM of COE catalyzed by $\mathbf{G 2}$ in the presence of CTA 1,2 or 3 at $40-60{ }^{\circ} \mathrm{C}$ for $24 \mathrm{~h}$.

\begin{tabular}{|c|c|c|c|c|c|c|c|c|c|}
\hline Entry & CTA & Solvent & $\begin{array}{l}\text { Temp. } \\
\left({ }^{\circ} \mathrm{C}\right)\end{array}$ & {$[\mathrm{COE}]_{0} /[\mathrm{CTA}]_{0} /[\mathbf{G} 2]_{0}{ }^{a}$} & $\begin{array}{c}\text { CTA } \\
\text { Conv. } \\
\%\end{array}$ & $\begin{array}{c}M_{n, \text { theo }}{ }^{c} \\
\left(\mathrm{~g} \cdot \mathrm{mol}^{-1}\right)\end{array}$ & $\begin{array}{c}M_{\mathrm{n}, \mathrm{NMR}}{ }^{d} \\
\left(\mathrm{~g} \cdot \mathrm{mol}^{-1}\right)\end{array}$ & $\begin{array}{c}M_{\mathrm{n}, \mathrm{SEC}}{ }^{e} \\
\left(\mathrm{~g} \cdot \mathrm{mol}^{-1}\right)\end{array}$ & $\bigoplus_{M}{ }^{e}$ \\
\hline 1 & $\mathbf{1}$ & $\mathrm{CH}_{2} \mathrm{Cl}_{2}$ & 40 & 1000:15:1 & 50 & 14900 & 11750 & 27200 & 1.5 \\
\hline 2 & 1 & $\mathrm{CH}_{2} \mathrm{Cl}_{2}$ & 40 & 2000:50:1 & 41 & 11000 & 6300 & 15900 & 1.4 \\
\hline 3 & 2 & $\mathrm{CH}_{2} \mathrm{Cl}_{2}$ & 40 & 1000:20:1 & 0 & $110000^{f}$ & & - & - \\
\hline 4 & 2 & $\mathrm{CH}_{2} \mathrm{Cl}_{2} / \mathrm{DMF}$ & 40 & 1000:20:1 & 100 & 5800 & 7400 & 23000 & 1.3 \\
\hline 5 & 2 & $\left(\mathrm{CH}_{2}\right)_{2} \mathrm{Cl}_{2}$ & 60 & 1000:20:1 & 100 & 5800 & 6200 & 14900 & 1.3 \\
\hline 6 & 3 & $\mathrm{CH}_{2} \mathrm{Cl}_{2}$ & 40 & 1000:20:1 & 100 & 5900 & 6300 & 15800 & 1.3 \\
\hline 7 & 3 & $\mathrm{CH}_{2} \mathrm{Cl}_{2}$ & 40 & 1000:40:1 & 100 & 3100 & 4200 & 11800 & 1.4 \\
\hline 8 & 3 & $\mathrm{CH}_{2} \mathrm{Cl}_{2}$ & 40 & 2000:40:1 & 100 & 5850 & 5900 & 15900 & 1.4 \\
\hline 9 & 3 & $\left(\mathrm{CH}_{2}\right)_{2} \mathrm{Cl}_{2}$ & 60 & 2000:100:1 & 52 & 4200 & 5800 & $-g$ & $-g$ \\
\hline 10 & $3^{h}$ & $\left(\mathrm{CH}_{2}\right)_{2} \mathrm{Cl}_{2}$ & 60 & 2000:100:1 & 100 & 2200 & 3100 & $-g$ & $-g$ \\
\hline
\end{tabular}

${ }^{a}$ General conditions: Catalyst $=5.9 \mu \mathrm{mol},[\mathrm{COE}]_{0}=1.8 \mathrm{~mol} \cdot \mathrm{L}^{-1}$; Quantitative COE conversion as determined by ${ }^{1} \mathrm{H}$ NMR analysis; reaction times were not optimized (refer to the Experimental Section). ${ }^{b} \mathrm{CTA}$ conversion determined by ${ }^{1} \mathrm{H}$ NMR analysis (refer to the Experimental Section). ${ }^{c}$ Theoretical molar mass value calculated from $M_{\mathrm{n}, \text { theo }}=\left\{M_{\mathrm{COE}} \times\left([\mathrm{COE}]_{0} \times\right.\right.$ Conv.COE $) /\left([\mathrm{CTA}]_{0} \times\right.$ Conv. $\left.\left.{ }_{\text {CTA }}\right)\right\}$ $+M_{\mathrm{CTA}}$ with $M_{\mathrm{COE}}=110 \mathrm{~g} \cdot \mathrm{mol}^{-1}, M_{\mathrm{CTA} 1}=250 \mathrm{~g} \cdot \mathrm{mol}^{-1}, M_{\mathrm{CTA} 2}==278 \mathrm{~g} \cdot \mathrm{mol}^{-1}, M_{\mathrm{CTA} 3}=357 \mathrm{~g} \cdot \mathrm{mol}^{-1}$, on the basis of the formation of only DF (i.e. without taking into account any CNF PCOEs). ${ }^{d}$ Experimental molar mass value determined by ${ }^{1} \mathrm{H}$ NMR analysis (refer to the Experimental Section). ${ }^{e}$ Number-average molar mass $\left(M_{\mathrm{n}, \mathrm{SEC}}\right)$ and dispersity $\left(\emptyset_{\mathrm{M}}=M_{\mathrm{w}} / M_{\mathrm{n}}\right)$ values determined by SEC vs polystyrene standards (uncorrected $M_{\mathrm{n}}$ values) in THF at $30^{\circ} \mathrm{C}^{\circ}{ }^{f}$ Theoretical molar mass value calculated from $M_{\mathrm{n}, \text { theo }}=[\mathrm{COE}]_{0} /$ [G2 $]_{0} \times$ Conv. $\mathrm{COE} \times M_{\mathrm{COE}}$ with $M_{\mathrm{COE}}=110 \mathrm{~g} \cdot \mathrm{mol}^{-1}$, on the basis of the formation of only non-functional PCOE. ${ }^{g}$ Unfortunately, SEC analyses could not be performed rapidly enough prior to the slow gelification of the sample under air (in ca. one month), probably due to oxidation processes. ${ }^{h}$ Experiment carried out with HG2.

The tandem ROMP/CM/RCM of COE in the presence of $\mathbf{G 2}$ and CTAs 1, 2, or $\mathbf{3}$ led, for all experiments, to the quantitative conversion of $\mathrm{COE}$ (Table 1). However, in $\mathrm{CH}_{2} \mathrm{Cl}_{2}$, CTA 1 was partially converted (ca. 50\%), thus suggesting a poor efficiency of CM (Table 1, entries 1-2). This poor reactivity of CTA 1 likely arises from the close proximity of the AZL group to the $\mathrm{C}=\mathrm{C}$ double bond which may electronically and sterically limit the reactivity and 
access of the alkene function to the ruthenium catalytic center. CTA 2 was completely ineffective in $\mathrm{CH}_{2} \mathrm{Cl}_{2}$ at $40{ }^{\circ} \mathrm{C}$ due to its insolubility. Addition of a more polar solvent (DMF/ $\mathrm{CH}_{2} \mathrm{Cl}_{2}, 90: 10 v / v$ ) enabled its dissolution, and $\mathrm{CM}$ could then proceed effectively (100\% conversion of CTA 2 ) (Table 1, entry 4). The complete solubilization of CTA 2 in 1,2dichloroethane at $60{ }^{\circ} \mathrm{C}$ similarly resulted in a homogeneous reaction medium and fully effective CM (Table 1, entry 5). The cyclohexyl moiety of CTA 3 improved its solubility and the CTA was then fully consumed when the polymerization was performed in $\mathrm{CH}_{2} \mathrm{Cl}_{2}$ at $40{ }^{\circ} \mathrm{C}$ (Table 1, entries 6-8). ROMP/CM of COE performed in 1,2-dichloroethane in the presence of CTA 3 also proceeded up to complete COE and CTA consumption at $60{ }^{\circ} \mathrm{C}$, using HG2 as catalyst (more efficient than G2 Table 1, entries 9-10).

All three symmetric CTAs $\mathbf{1}, \mathbf{2}$ and $\mathbf{3}$ thus enabled the formation of $\alpha, \omega$-di(AZL) telechelic PCOEs (DF), as evidenced by NMR spectroscopy and MALDI-ToF MS (vide infra, Figures 1-3, S10-S15). Besides, minor amounts of cyclic polymer (CNF) formed, as further confirmed thereafter and similarly to our previous investigations on related symmetric alkene CTAs. ${ }^{32,34}$ Under the best established operating conditions, the PCOEs recovered displayed a molar mass determined by NMR analysis $\left(M_{\mathrm{n}, \mathrm{NMR}}\right)$ in good agreement with the molar mass calculated on the basis of the formation of only DF PCOEs $\left(M_{\text {n,theo }}\right)$ (i.e. without taking into account any CNF nor any non-functional PCOEs; refer to the Experimental Section). The difference observed between $M_{\mathrm{n}, \mathrm{NMR}}$ and $M_{\mathrm{n}, \text { theo }}$ with the molar mass values measured from $\operatorname{SEC}\left(M_{\mathrm{n}, \mathrm{SEC}} ; M_{\mathrm{n}, \mathrm{SEC}}=\right.$ ca. $\left.2.5-2.8 M_{\mathrm{n}, \mathrm{NMR}}\right)$, as similarly reported in the literature, ${ }^{32-35}$ reflects the difference in hydrodynamic radius between PCOEs and polystyrenes used as standards for the calibration of the SEC apparatus; interactions of the AZL chain-ends in macromolecules with the column support cannot be excluded yet. The dispersity data remained in the range 1.3-1.5 which are typical for metathesis polyolefins in the presence of a CTA. ROMP of COE performed with $\mathbf{G 2}$ catalyst using CTAs $\mathbf{1}, \mathbf{2}$ or $\mathbf{3}$ was thus well-controlled in terms of molar 
mass values and relatively narrow dispersity data, selectively affording mainly $\alpha, \omega$-di(AZL) telechelic PCOEs (DF), with turnover numbers $\left(\mathrm{TON}=\operatorname{mol}_{\mathrm{COE}} \cdot \mathrm{mol}_{\mathrm{Ru}}{ }^{-1}\right.$; not optimized) up to 2000 in ROMP and up to $100\left(\mathrm{TON}=\operatorname{mol}_{\mathrm{CTA}} \cdot \mathrm{mol}_{\mathrm{Ru}}{ }^{-1}\right.$; not optimized $)$ in CM (Table 1 , entries 9,10). CTA 3 bearing the cyclohexyl-substituted AZL function appeared to afford the best compromise in terms of activity and productivity under the operating conditions implemented, while providing solubility to the recovered PO material.

\section{Azlactone telechelic copolyolefins: ROMP of NB/CDT catalyzed by G2 in the presence of}

CTAs 3. Low viscosity liquid copolyolefins were next targeted using CTA 3. The molar ratio of comonomers was set at 50:50, as previously optimized for the preparation of low viscosity liquid POs (Scheme 5). ${ }^{34}$ Illustrative results are gathered in Table 2.

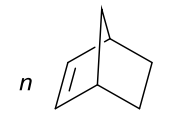

NB

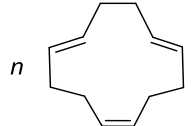

CDT

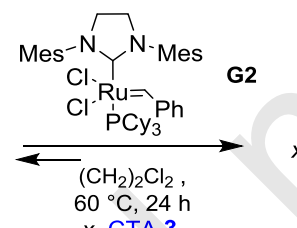

$x$ CTA 3
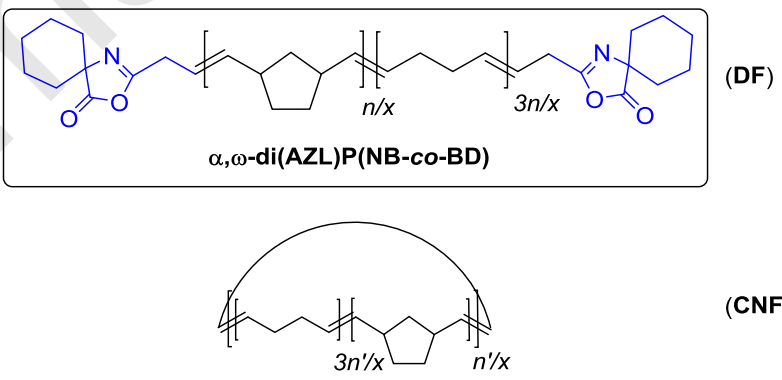

(CNF)

Scheme 5. Synthesis of AZL-functional copolyolefins by the tandem ROMP/CM/RCM of NB and CDT catalyzed by $\mathbf{G} 2$ in the presence of CTA 3 (DF: $\alpha, \omega$-difunctional, CNF: cyclic nonfunctional). 
Table 2. Copolymerization of NB and CDT (50:50 mol/mol) catalyzed by $\mathbf{G 2}$ or $\mathbf{H G 2}$ in the presence of CTA 3 in 1,2-dichloroethane at $60{ }^{\circ} \mathrm{C}$ for $24 \mathrm{~h}$.

\begin{tabular}{|c|c|c|c|c|c|c|c|c|c|}
\hline \multirow[b]{2}{*}{ Entry } & \multirow[b]{2}{*}[\mathrm{NB}]{$_{0} /[\mathrm{CDT}]_{0} /[\mathrm{CTA}]_{0} /[\mathbf{G} 2]_{0}{ }^{a}$} & \multirow{2}{*}{$\begin{array}{c}M_{n, \text { theo }}{ }^{b} \\
\left(\mathrm{~g} \cdot \mathrm{mol}^{-1}\right)\end{array}$} & \multirow{2}{*}{$\begin{array}{l}M_{\mathrm{n}, \mathrm{NMR}}{ }^{c} \\
\left(\mathrm{~g} \cdot \mathrm{mol}^{-1}\right)\end{array}$} & \multirow{2}{*}{$\begin{array}{c}M_{\mathrm{n}, \mathrm{SEC}}{ }^{d} \\
\left(\mathrm{~g} . \mathrm{mol}^{-1}\right)\end{array}$} & \multirow[b]{2}{*}{$\bigoplus_{\mathrm{M}}^{d}$} & \multicolumn{3}{|c|}{ CNF } & \multirow{2}{*}{$\begin{array}{c}\mathrm{C}_{\mathrm{AZL}}{ }^{f} \\
\left(\mathrm{mmol} . \mathrm{g}^{-1}\right)\end{array}$} \\
\hline & & & & & & $(\mathrm{wt} \%)^{e}$ & $\begin{array}{r}M_{\mathrm{n}, \mathrm{sec}}{ }^{d} \\
\left(\mathrm{~g} \cdot \mathrm{mol}^{-1}\right)\end{array}$ & $\bigoplus_{\mathrm{M}}{ }^{d}$ & \\
\hline 1 & 1000:1000:80:1 & 3600 & 4000 & 6000 & 1.6 & 2 & 7500 & 1.2 & - \\
\hline 2 & 2000:2000:80:1 & 6800 & 6700 & 18700 & 1.3 & 17 & 20100 & 1.1 & - \\
\hline 3 & 2000:2000:80:1 & 6800 & 6900 & 11800 & 1.6 & 7 & 13200 & 1.2 & - \\
\hline 4 & 5000:5000:200:1 & 6800 & 6600 & 16000 & 1.6 & 14 & 13200 & 1.2 & - \\
\hline $5^{g}$ & 1000:1000:100:1 & 2560 & 1900 & 7600 & 1.6 & n.d. & n.d. & n.d. & 0.82 \\
\hline \multicolumn{10}{|c|}{ 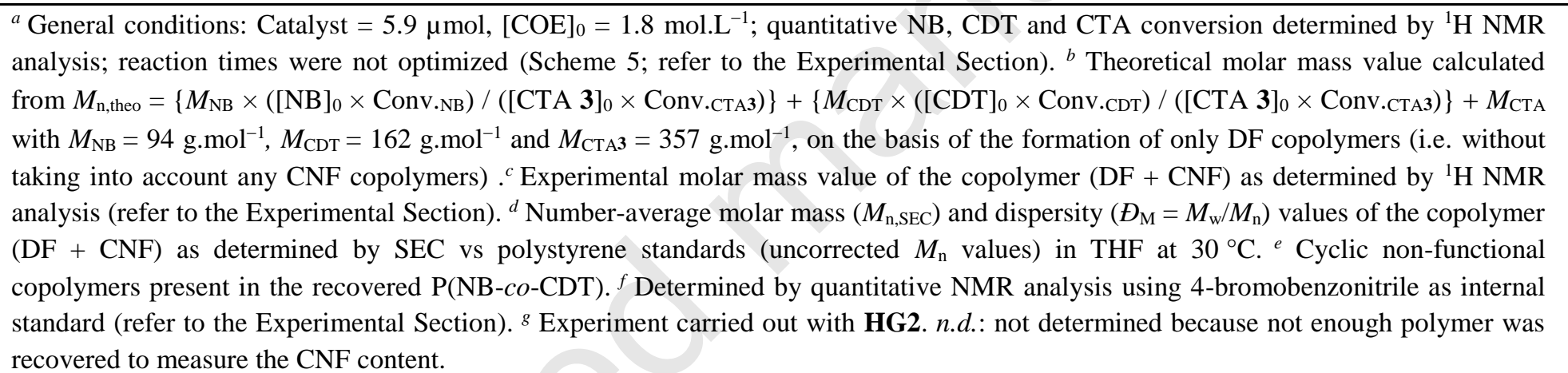 } \\
\hline
\end{tabular}

The tandem ROMP/CM/RCM of an equimolar mixture of NB and CDT (50:50; catalyzed by G2/CTA 3 in 1,2-dichloroethane at $60{ }^{\circ} \mathrm{C}$ for $24 \mathrm{~h}$ ) afforded $\alpha, \omega$-di(AZL)P(NB$c o$-CDT) with a good control of the macromolecular characteristics $\left(M_{\mathrm{n}, \mathrm{NMR}}\right.$ in good agreement with $M_{\mathrm{n}, \text { theo }} ; \bigoplus_{\mathrm{M}}$ ) of the random copolymers. Rather fair TONs of ROMP up to 5000 and TONs of CM up to 200 were reached with larger loadings of comonomers (Table 2, entry 4). As evidenced above for the metathesis of COE using di(AZL) functional olefin CTAs, and similarly to other ROMP/CM using symmetric CTAs (such as in particular diepoxide-, di(cyclodithiocarbonate)-, or bis(trialkoxysilyl)-bearing CTAs), ${ }^{12,32,34}$ the desired difunctional random copolymers (DFs) were recovered as the main copolymers (typically 
83-98wt\%); only minor amounts (typically 5-17wt\%) of CNF side products formed under these conditions (Scheme 5, vide infra). The random nature of the copolymers originates from the tandem ROMP/CM/RCM process implemented with the simultaneous introduction of both comonomers and from a similar reactivity of both comonomers in metathesis reactions.

Structural characterization of the azlactone telechelic (co)polyolefins. ${ }^{1} \mathrm{H}$ and ${ }^{13} \mathrm{C}\left\{{ }^{1} \mathrm{H}\right\}$ NMR analyses of PCOEs prepared from CTAs 1, 2, or $\mathbf{3}$ all evidenced the formation of DF (and possibly CNF; vide infra) as the only products, respectively, as illustrated Figures 1-2, S10-S12 (Scheme 4). The characteristic main chain olefin hydrogens $\left(\mathrm{H}^{1}-\mathrm{H}^{3}, \mathrm{C}^{1}-\mathrm{C}^{3}\right)$ were clearly observed along with the signals typical of the azlactone end-groups ( $\delta(\mathrm{ppm}) \mathrm{CTA}$ 1,2,3: 5.79-5.65 $\left(\mathrm{H}^{\mathrm{a}}\right)$, 5.52-5.38 $\left(\mathrm{H}^{\mathrm{b}}\right), 3.21-3.17\left(\mathrm{H}^{\mathrm{c}}\right)$; CTA 1, 2: $1.53\left(\mathrm{H}^{\mathrm{d}}\right)$; CTA 3: 1.61, 1.79, $\left(\mathrm{H}^{\mathrm{d}}, \mathrm{H}^{\mathrm{e}}\right)$; CTA 1,2,3: ca. 137.1,121.1,47.0 $\left(\mathrm{C}^{\mathrm{a}}, \mathrm{C}^{\mathrm{b}}, \mathrm{C}^{\mathrm{c}}\right)$; CTA 2: $25.0,176.0,173.3,57.4$ $\left(C^{\mathrm{d}}-\mathrm{C}^{\mathrm{g}}\right)$; CTA 3: 68.0,33.6,21.1,24.0 $\left(\mathrm{C}^{\mathrm{f}}-\mathrm{C}^{\mathrm{i}}\right), 162.2,180.7\left(\mathrm{C}^{\mathrm{d}}, \mathrm{C}^{\mathrm{e}}\right)$, respectively). Note that the NMR signals for the CNF PCOE are identical to those of the COE repeating unit $\left(\mathrm{H}^{1}-\mathrm{H}^{3}\right.$, $\mathrm{C}^{1}-\mathrm{C}^{3}$ ) in DF, thus precluding quantification of DF vs CNF PCOEs. However, the amount of CNF previously determined for the alike ROMP/CM/RCM of cyclic olefins was reported not to exceed $20 \%$ (see also the CNF content in the NB/CDT copolymers which remained < $17 \mathrm{wt} \%$; Table 2). ${ }^{32-34}$ 


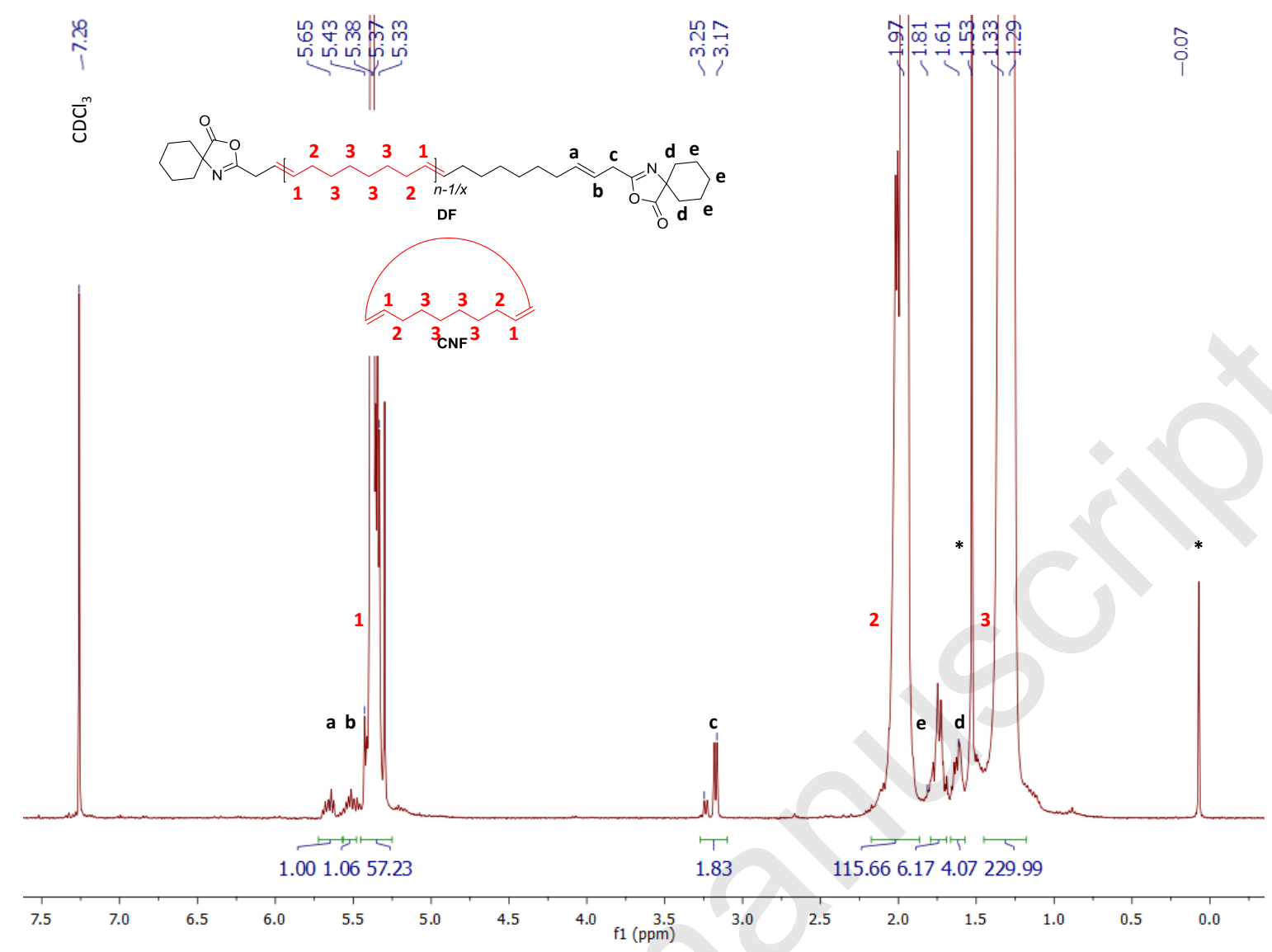

Figure 1. ${ }^{1} \mathrm{H}$ NMR spectrum $\left(500 \mathrm{MHz}, \mathrm{CDCl}_{3}, 25^{\circ} \mathrm{C}\right)$ of the polymer sample prepared by $\mathrm{ROMP} / \mathrm{CM} / \mathrm{RCM}$ of $\mathrm{COE}$ catalyzed by $\mathbf{G} 2$ in the presence of CTA 3 in $\mathrm{CH}_{2} \mathrm{Cl}_{2}$, showing DF and CNF PCOEs (Table 1, entry 6) (*: residual impurities at $\delta$ (ppm) $1.53 \mathrm{H}_{2} \mathrm{O}, 0.07$ grease). Also the distinctive signals of MF (allyl methylene terminus, $\delta_{\mathrm{CH} 2} 5.15,4.90 \mathrm{ppm}$ ) and its isomerized analogue IMF (methyl group of the propenyl end-moiety, $\delta 1.64 \mathrm{ppm}$ ) are clearly not observed, as expected (Scheme 4). 


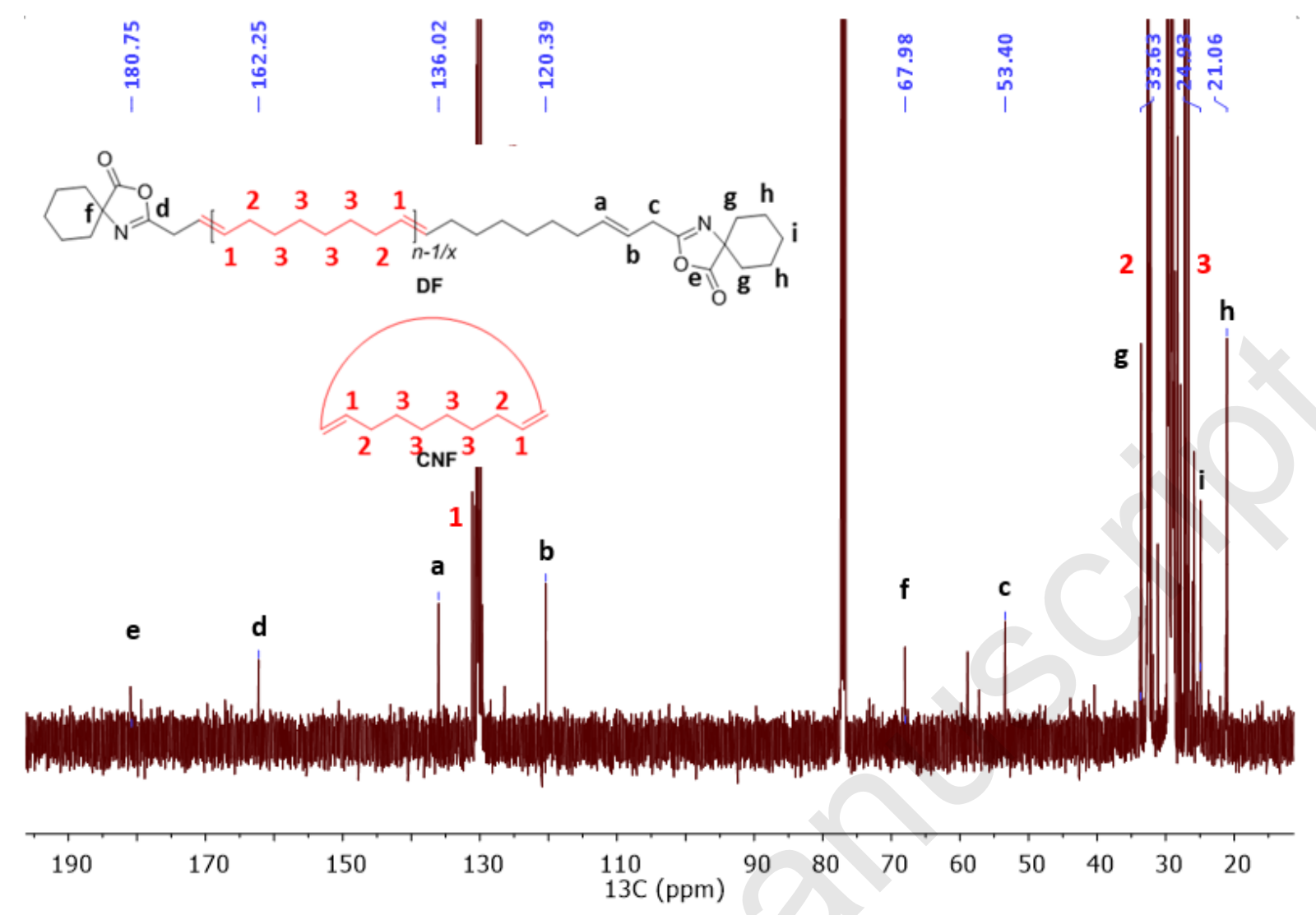

Figure 2. ${ }^{13} \mathrm{C}\left\{{ }^{1} \mathrm{H}\right\}$ NMR spectrum $\left(125 \mathrm{MHz}, \mathrm{CDCl}_{3}, 25{ }^{\circ} \mathrm{C}\right)$ of the polymer sample prepared by ROMP/CM/RCM of COE catalyzed by $\mathbf{G 2}$ in the presence of CTA 3 in $\mathrm{CH}_{2} \mathrm{Cl}_{2}$, showing DF and CNF PCOEs (Table 1, entry 6).

MALDI-ToF MS analyses of the homopolymer samples obtained from CTAs 1, 2, or 3 were acquired using a sodium salt or a silver salt as cationizing agent, so as to probe the presence of either DF PCOE and/or CNF PCOEs, respectively (Figures 3, S13-S15, respectively). All spectra of the three AZL end-capped PCOEs, showed a major population of PCOE with a repeating unit of 110 g.mol ${ }^{-1}$ end-capped with two azlactone moieties, namely DF PCOE, with e.g. $m / z$,experimentalCTA1 $=1017.7$ g. $\mathrm{mol}^{-1}$ for $n=6($ Figure 3$) ; m / z$,experimentalCTA2 $=1483.1$ g.mol ${ }^{-1}$ for $n=10$ (Figure S13), respectively. This was unequivocally supported by the close match of the simulated isotopic distribution of the DF PCOE with e.g. $m / z$,simulatedCTA1 $=1017.6$ g. $\mathrm{mol}^{-1}$ for $n=6($ Figure 3$) ; m / z$, simulatedCTA2 $=1483.3 \mathrm{~g} \cdot \mathrm{mol}^{-1}$ for $n=$ 
10 (Figure S13), respectively. The other minor population observed when CTAs 1 and $\mathbf{3}$ were used, was unambiguously assigned to CNF PCOE with e.g. $\mathrm{m} / z_{\text {,experimentalCTA1 }}=989.7$ g.mol ${ }^{-1}$ vs $m / z$, simulatedCTA $1=989.8$ g. $\mathrm{mol}^{-1}$ for $m=8($ Figure 3$) ; \mathrm{m} / z_{\text {,experimentalCTA2 }}=1430.1 \mathrm{~g} \cdot \mathrm{mol}^{-1} v s$ $m / z_{\text {,simulatedCTA2 }}=1430.2 \mathrm{~g} \cdot \mathrm{mol}^{-1}$ for $m=12\left(\right.$ Figure S14); $\mathrm{m} / z_{\text {,experimentalCTA3 }}=1430.2 \mathrm{~g} \cdot \mathrm{mol}^{-1}$ vs $m / 2$, simulatedCTA3 $=1430.2 \mathrm{~g} \cdot \mathrm{mol}^{-1}$ for $m=12($ Figure S15).

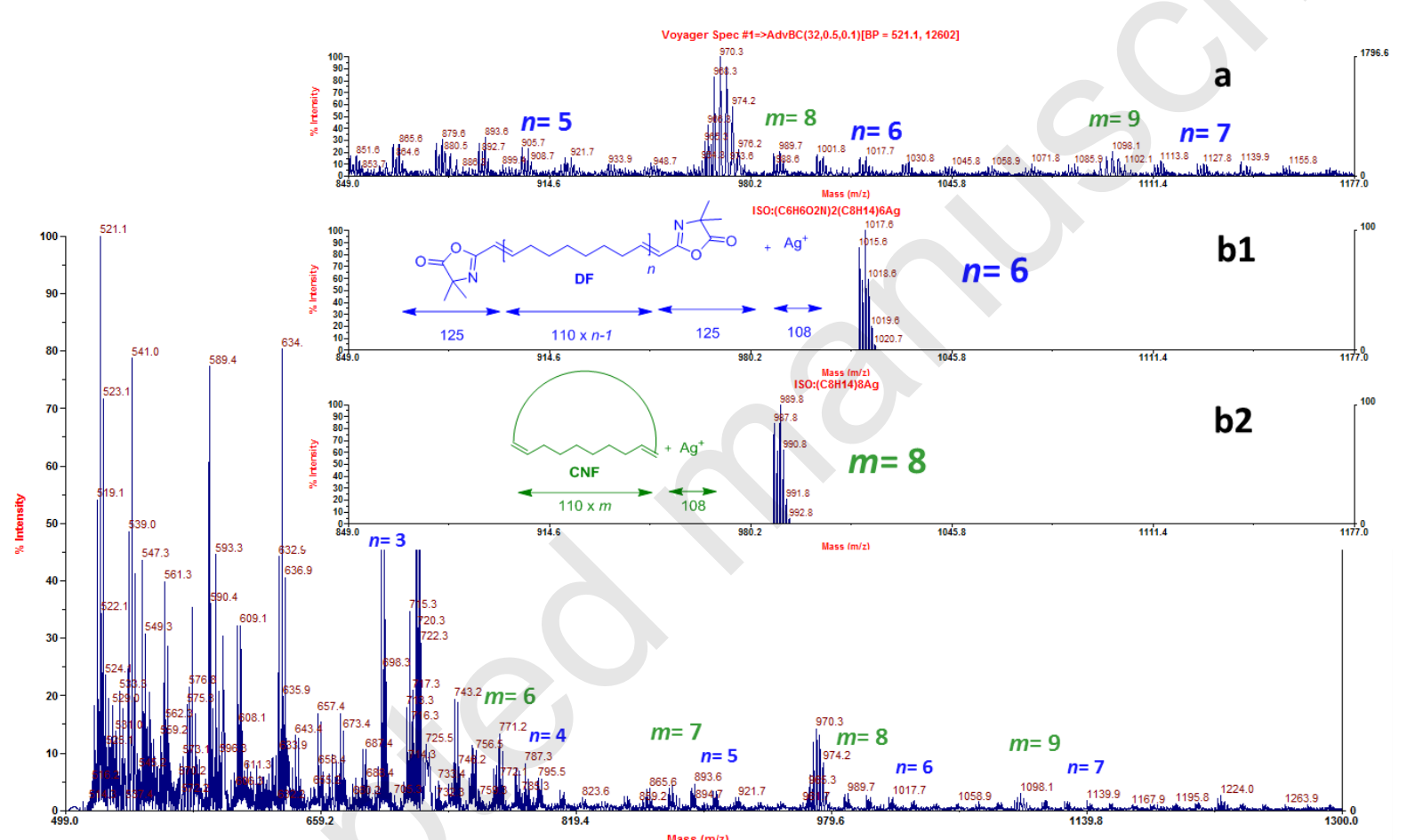

Figure 3. MALDI-ToF mass spectrum (DCTB matrix, AgTFA ionizing salt) of a polymer sample prepared by ROMP/CM/RCM of COE catalyzed by $\mathbf{G 2}$ in the presence of CTA 1 (Table 1, entry 1) showing a mixture of DF and CNF PCOEs; see top zoomed region and the corresponding middle and bottom simulations for $n=6$ and $m=8$, respectively.

The macromolecular structure of the copolymers isolated from the random copolymerization of an equimolar mixture of NB and CDT catalyzed by $\mathbf{G 2}$ in the presence of CTA 3 (Scheme 5) was similarly investigated by NMR spectroscopy. Close insights of the 
spectra revealed that the AZL moiety was bonded to either a butadiene or a 1,3-divinylenecyclopentane ultimate unit (Figures 4, S17-S18). Indeed, two distinct methine signals corresponding to the bonding of the AZL function to either a NB or CDT unit, were clearly identified $\left(\delta(\mathrm{ppm}) 6.74\left(\mathrm{H}^{\mathrm{A}^{\prime}}\right), 6.01\left(\mathrm{H}^{\mathrm{B}}\right)\right.$, and $5.65\left(\mathrm{H}^{\mathrm{a}, \mathrm{b}}\right)$ in black, respectively) (Figure 4). This observation was further supported by a $2 \mathrm{D}{ }^{1} \mathrm{H}-{ }^{1} \mathrm{H}$ COSY NMR analysis (Figure S17). While the methine hydrogens $\mathrm{H}^{\mathrm{a}, \mathrm{b}}$ are coupled to $\mathrm{H}^{2}$, which corresponds to a butadiene unit, $\mathrm{H}^{\mathrm{a}, \mathrm{b}}$ do not show any correlation to $\mathrm{H}^{6 \text { trans,6cis }}$. Furthermore and inversely, the couplings of $\mathrm{H}^{\mathrm{A}^{\mathrm{\prime}}}$ and $\mathrm{H}^{\mathrm{B}}$ to $\mathrm{H}^{6 t r a n s}$ and $\mathrm{H}^{6 c i s}$ and the absence of correlation between $\mathrm{H}^{\mathrm{A}^{\prime}} / \mathrm{H}^{\mathrm{B}}$ and $\mathrm{H}^{2}$ support the AZL end-capping onto either a divinyl cyclopentane or a butadiene unit. ${ }^{13} \mathrm{C}\left\{{ }^{1} \mathrm{H}\right\}$ NMR analysis further corroborated the formation of a $\alpha, \omega$-diazlactone telechelic P(NB-co-CDT). The PCDT $\left(\mathrm{C}^{1}, \mathrm{C}^{2}, \mathrm{C}^{4}\right.$ in red) and PNB $\left(\mathrm{C}^{5}-\mathrm{C}^{8}\right.$ in green $)$ signals were observed along with those of the AZL end-function $\left(\mathrm{C}^{\mathrm{a}}-\mathrm{C}^{\mathrm{h}}, \mathrm{C}^{\mathrm{A}^{\prime}}\right.$ and $\mathrm{C}^{\mathrm{B}^{\prime}}$; in black, Figure $\left.\mathrm{S} 18\right)$, further supporting AZL end-capping onto either a NB or a CDT unit. The coexistence in a copolymer of both type of comonomers as penultimate chain end-units adjacent to an (in the present case AZL) end-function prepared by metathesis polymerization using a catalyst and an alkene CTA, presently a cyclohexyl-azlactone function (CTA 3), has, to our knowledge, never been observed with any other CTAs. Indeed, with epoxide or trialkoxysilyl CTAs, end-capping (i.e., CM) proved to be selective of butadiene moieties. ${ }^{32,33,34}$ 


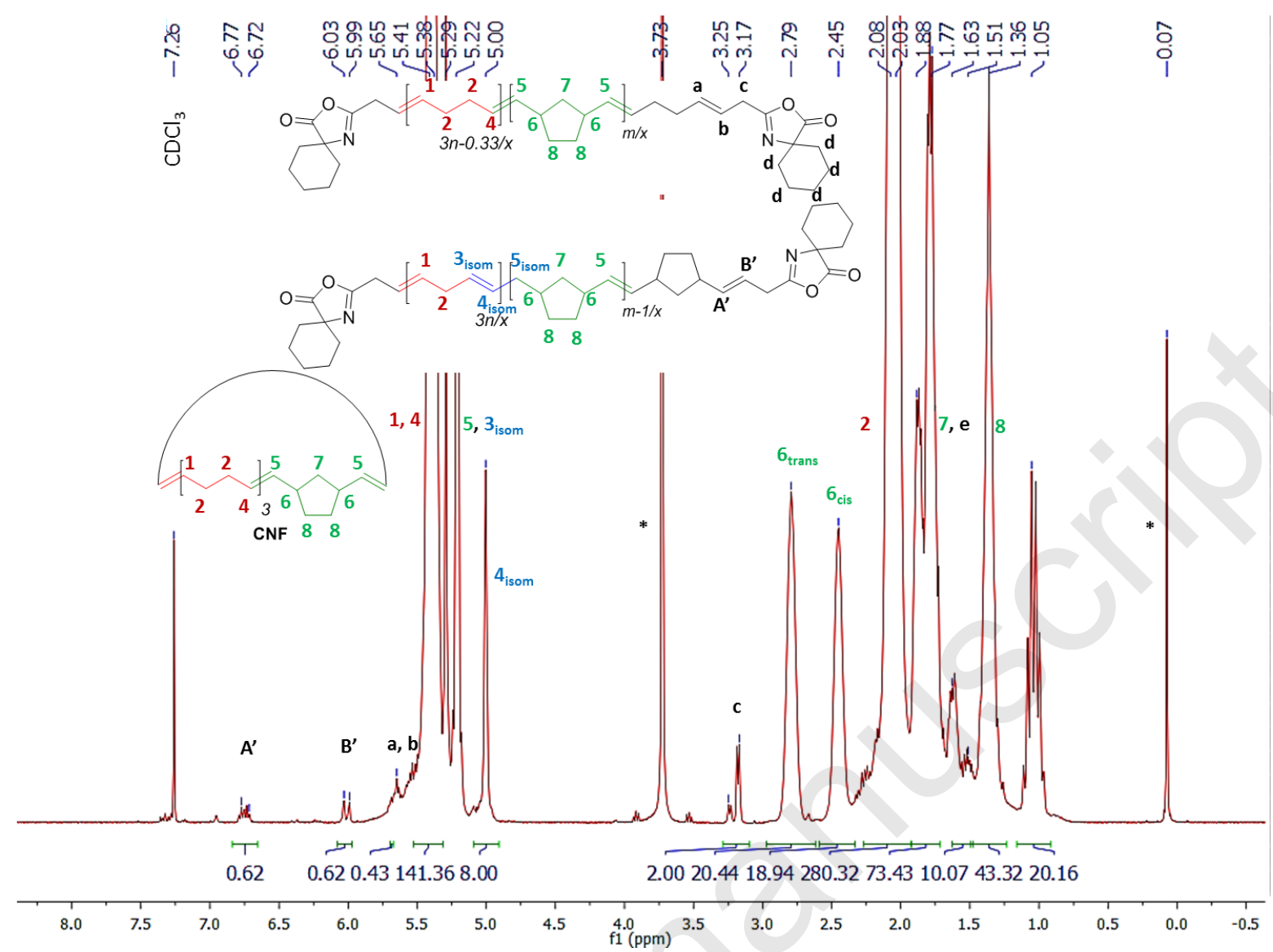

Figure 4. ${ }^{1} \mathrm{H}$ NMR spectrum $\left(500 \mathrm{MHz}, \mathrm{CDCl}_{3}, 25^{\circ} \mathrm{C}\right)$ of the copolymer sample prepared by ROMP/CM/RCM of a 50:50 NB/CDT mixture catalyzed by $\mathbf{G} 2$ in the presence of CTA 3 in 1,2-dichloroethane, showing the NB-AZL and CDT-AZL chain-end moieties (Table 2, entry 2) $\left(*\right.$ residual impurities: $\delta(\mathrm{ppm}) 3.73\left(\mathrm{CH}_{2}\right)_{2} \mathrm{Cl}_{2}$, 0.07 grease)

Thermal and rheological properties of $\operatorname{di}(\mathrm{AZL})$ telechelic (co)polyolefins. The thermal and rheological behavior of the $\alpha, \omega$-di(AZL) telechelic (co)POs was briefly investigated by DSC and viscosimetry, respectively (Table 3). 
Table 3. Apparent physical state, thermal transition temperatures, Newtonian viscosity and rheological behavior of $\alpha, \omega$-di(AZL) telechelic (co)POs synthesized by ROMP/CM/RCM of COE with NB or CDT catalyzed by $\mathbf{G 2}$ in the presence of CTAs $\mathbf{1}, \mathbf{2}$, or $\mathbf{3}$ for $24 \mathrm{~h}$ with $[(\mathrm{co}) \text { monomer }]_{0} /[\mathrm{CTA}]_{0} /[\mathbf{G} 2]_{0}=1000: 20: 1$, as determined by DSC and viscosimetry

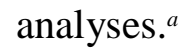

\begin{tabular}{|c|c|c|c|c|c|c|c|c|c|c|}
\hline \multirow{4}{*}{ Entry } & \multirow{4}{*}{ CTA } & \multirow{4}{*}{ Polymer } & \multicolumn{4}{|c|}{ Apparent } & \multicolumn{4}{|c|}{ Newtonian } \\
\hline & & & $M_{\mathrm{n}, \mathrm{NMR}}{ }^{b}$ & & $T_{\mathrm{g}}{ }^{c}$ & $T_{\mathrm{m}}{ }^{c}$ & $T_{\mathrm{c}}{ }^{c}$ & $\Delta \mathrm{H}_{\text {fus }}{ }^{c}$ & viscosity $^{d}$ & \\
\hline & & & $\left(\mathrm{g} \cdot \mathrm{mol}^{-1}\right)$ & state & $\left({ }^{\circ} \mathrm{C}\right)$ & $\left({ }^{\circ} \mathrm{C}\right)$ & $\left({ }^{\circ} \mathrm{C}\right)$ & $(\mathrm{J} / \mathrm{g})$ & & behavior \\
\hline & & & & at $23{ }^{\circ} \mathrm{C}$ & & & & & (Pa.s) & \\
\hline 1 & 1 & PCOE & 11750 & solid & $n . o$ & 57 & 45 & 24 & - & - \\
\hline 2 & 2 & PCOE & 5800 & solid & n.o & 55 & 40 & 25 & - & - \\
\hline 3 & 3 & PCOE & 5900 & solid & n.o & 56 & 47 & 27 & - & - \\
\hline 4 & 3 & $\mathrm{P}(\mathrm{NB}-\mathrm{co}-\mathrm{CDT})$ & 1900 & liquid & -60 & 4 & -14 & 13 & - & - \\
\hline 5 & 3 & $\mathrm{P}(\mathrm{NB}-\mathrm{co}-\mathrm{CDT})$ & 4000 & liquid & n.o. & 7 & -18 & 10 & 16 & Shear-thinning \\
\hline 6 & 3 & $\mathrm{P}(\mathrm{NB}-c o-\mathrm{CDT})$ & 6900 & liquid & n.o. & 7 & -18 & 6 & 15 & Shear-thinning \\
\hline $\begin{array}{l}{ }^{a} \text { Poly1 } \\
\text { perform } \\
\text { Section } \\
\text { accordi } \\
120^{\circ} \mathrm{C} \\
\text { viscosil }\end{array}$ & $\begin{array}{l}\text { izatio } \\
\text { at } 60 \\
\text { ables } \\
\text { to the } \\
10^{\circ} \mathrm{C}\end{array}$ & $\begin{array}{l}\text { in entries } 1-3 \mathrm{w} \\
\mathrm{C} \text { in }\left(\mathrm{CH}_{2}\right)_{2} \mathrm{Cl}_{2}(\mathrm{Ta} \\
-2) .{ }^{c} \mathrm{Glass}_{\mathrm{a}} \mathrm{transit} \\
\text { ollowing cycles: } \\
\text { in }^{-1} ; 120^{\circ} \mathrm{C} \text { to }- \\
\text { rtainty }= \pm 5 \% . n\end{array}$ & $\begin{array}{l}\text { performe } \\
\text { 2) }{ }^{b} \text { Expe } \\
\text { melting a } \\
{ }^{\circ} \mathrm{C} \text { to } 12 \\
{ }^{\circ} \text { at } 10^{\circ}\end{array}$ & $\begin{array}{l}40^{\circ} \mathrm{C} \text { in } \\
\text { nental molal } \\
\text { crystallizat } \\
\mathrm{C} \text { at } 10^{\circ} \mathrm{C} \\
\mathrm{min}^{-1} \cdot{ }^{d} \mathrm{~N} \\
\text { d. }\end{array}$ & $\begin{array}{l}{ }_{2} \mathrm{Cl}_{2} \\
\text { ass v } \\
\text { tem } \\
{ }^{-1} \text {; } \\
\text { onia }\end{array}$ & $\begin{array}{l}\text { ture } \\
{ }^{\circ} \mathrm{C} \\
\mathrm{scos}\end{array}$ & $\begin{array}{l}\text { Cop } \\
\text { nec } \\
\text { an n } \\
70^{\circ}\end{array}$ & $\begin{array}{l}\text { rizatic } \\
\text { H NM } \\
\text { g enth } \\
10^{\circ} \mathrm{C} \text {. } \\
\text { at } 23\end{array}$ & $\begin{array}{l}\text { using CTA } \\
\text { nalysis (refer } \\
\text { as determin } \\
{ }^{-1},-70^{\circ} \mathrm{C} \mathrm{f} \\
\text { with a Cont }\end{array}$ & $\begin{array}{l}\text { (entries } 4-6) \text { were } \\
\text { o the Experimental } \\
\text { d by DSC analyses } \\
\text { I } 5 \text { min; }-70^{\circ} \mathrm{C} \text { to } \\
\text { ives Low Shear } 30\end{array}$ \\
\hline
\end{tabular}

The apparent physical state of the (co)polymers at room temperature changed from solid for $\alpha, \omega$-di(AZL) telechelic PCOE homopolymers to liquid, low viscosity for $\alpha, \omega$-di(AZL) telechelic P(NB-co-CDT) copolymers. All $\alpha, \omega$-di(AZL) PCOEs displayed the same thermal signature, with no glass transition observed, a melting $\left(T_{\mathrm{m}}=\mathrm{ca} .55{ }^{\circ} \mathrm{C}\right)$ and crystallization $\left(T_{\mathrm{c}}=\right.$ ca. $\left.44{ }^{\circ} \mathrm{C}\right)$ temperatures which basically remained unaffected by the presence or not of the additional methylene next to the alkene (arising from a distinct CTA, $\mathbf{1}$ vs 2), and/or by the AZL-cyclohexyl substituent within CTA 3 (Table 3, entries 1-3; Figure 
S16). Also, the nature of the AZL end-function did not significantly impact the thermal behavior of the resulting $\alpha, \omega$-di(AZL)-functional PCOEs, as compared to related PCOEs endcapped with other functional groups such as glycidyl alkenoate $\left(M_{\mathrm{n}, \mathrm{NMR}}=6500 \mathrm{~g} \cdot \mathrm{mol}^{-1}, T_{\mathrm{g}}=\right.$ not observed, $\left.T_{\mathrm{m}}=57^{\circ} \mathrm{C}, T_{\mathrm{c}}=45^{\circ} \mathrm{C}\right),{ }^{12}$ carboxylate $\left(M_{\mathrm{n}, \mathrm{NMR}}=5000 \mathrm{~g} \cdot \mathrm{mol}^{-1}, T_{\mathrm{g}}=\right.$ not observed, $\left.T_{\mathrm{m}}=62{ }^{\circ} \mathrm{C}, T_{\mathrm{c}}=51{ }^{\circ} \mathrm{C}\right),{ }^{15}$ or dithiocarbonate $\left(M_{\mathrm{n}, \mathrm{NMR}}=6500 \mathrm{~g} \cdot \mathrm{mol}^{-1}, T_{\mathrm{g}}=\right.$ not observed, $\left.T_{\mathrm{m}}=56{ }^{\circ} \mathrm{C}, T_{\mathrm{c}}=43{ }^{\circ} \mathrm{C}\right)^{12}$ functions at both termini; only did the PCOE endfunctionalized with two trimethoxysilyl group exhibited a clear $T_{\mathrm{g}}$ in the investigated temperature range $\left(M_{\mathrm{n}, \mathrm{NMR}}=2900 \mathrm{~g} \cdot \mathrm{mol}^{-1}, T_{\mathrm{g}}=-78^{\circ} \mathrm{C}, T_{\mathrm{m}}=52{ }^{\circ} \mathrm{C}, T_{\mathrm{c}}=45^{\circ} \mathrm{C}\right) .{ }^{34}$ Furthermore, it has been reported that the melting temperature of PCOE depends on the $\mathrm{C}=\mathrm{C}$ double bond cis/trans configuration within macromolecules, with lower trans content exhibiting lower $T_{\mathrm{m}}$ and $T_{\mathrm{c}}$ values. ${ }^{8,59,60}$ For PCOEs featuring 20 to $99 \%$ of cis double bonds, the $T_{\mathrm{m}}$ value was therein shown to vary from $54{ }^{\circ} \mathrm{C}$ to $10{ }^{\circ} \mathrm{C}$. Thus, correlation with the $T_{\mathrm{m}}$ values recorded for the present AZL-functional PCOEs $\left(T_{\mathrm{m}}=\mathrm{ca} .55^{\circ} \mathrm{C}\right)$ enables to assess the extent of cis stereoisomers within the olefin repeating units of the AZL-difunctional PCOEs to ca. 20\%. For the $\alpha, \omega$-di(AZL)P(NB-co-CDT) random copolymers prepared from CTA 3 , the glass transition temperature could not be observed in the temperature range investigated. The melting temperature of the copolymers $\left(T_{\mathrm{m}}=\right.$ ca. $\left.6{ }^{\circ} \mathrm{C}\right)$ significantly decreased (by ca. $50{ }^{\circ} \mathrm{C}$ ) as compared to that of the PCOE, thus highlighting the benefit of copolymerizing CDT with NB so as to get lower viscosity liquid polymer materials, as previously observed (Figure S19). ${ }^{34}$ Correspondingly, the crystallization temperature similarly decreased (by ca. $62{ }^{\circ} \mathrm{C}$ ) upon copolymerizing CDT with NB.

\section{Model reaction for the synthesis of PAs: reactivity of a primary diamine towards CTA 3.}

The model equimolar reaction between the molecular CTA 3 and EDR-148 $\left(\mathrm{CH}_{2} \mathrm{Cl}_{2}, 40{ }^{\circ} \mathrm{C}\right)$ enabled to assess the reactivity of the AZL moiety towards a primary diamine and to 
characterize the resulting PA (Scheme 6). Precipitation of the polymer ultimately gave a white powder, partially soluble in $\mathrm{CHCl}_{3}$ and THF, and fully soluble in DMSO.

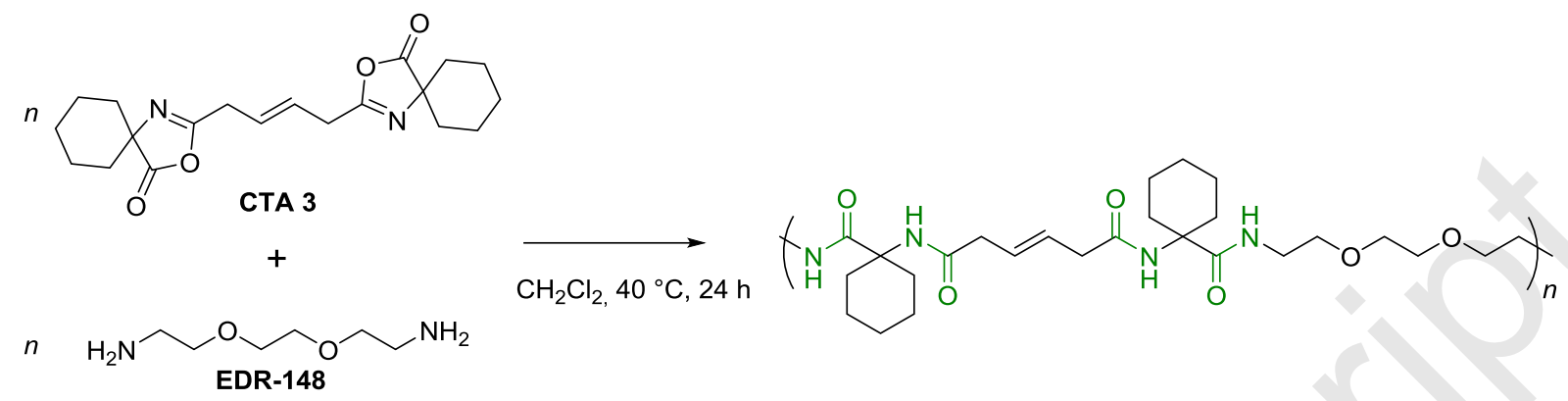

Scheme 6. Model reaction of an AZL moiety with a diamine: polyaddition of CTA 3 with EDR-148.

The ${ }^{1} \mathrm{H}$ and J-MOD NMR spectra of the recovered sample were recorded in DMSO- $d_{6}$ (Figures 5, S20). They were analyzed on the basis of the expected structure depicted in Scheme 6, along with the contribution of COSY, HSQC and HMBC spectra and upon comparison to CTA 3 (Figures S21-S23). The upfield chemical shift of the methine hydrogens (from $\mathrm{H}^{\mathrm{a}}, \delta 5.79$ to $\mathrm{H}^{\mathrm{a}^{\prime}}, 5.59 \mathrm{ppm}$; from $\mathrm{H}^{\mathrm{b}}, \delta 3.33$ to $\mathrm{H}^{\mathrm{b}^{\prime}}, 2.96 \mathrm{ppm}$, and from $\mathrm{H}^{\mathrm{f}}, \delta$ 2.62 to $\left.\mathrm{H}^{\mathrm{f}}, 3.17 \mathrm{ppm}\right)$, along with the splitting of the cyclohexyl signals $\left(\mathrm{H}^{\mathrm{c}-\mathrm{e}}\right.$ vs $\left.\mathrm{H}^{\mathrm{c}^{\prime}-\mathrm{e}^{\prime}}\right)$, evidenced a change in their close chemical environment (Figure 5). Unexpectedly, the $\mathrm{N}-\mathrm{H}$ signals from the amide functions recorded in the range $\delta 7.0-7.7 \mathrm{ppm}$ appeared as several sharp resonances, most likely due to strong intra- and/or inter-molecular hydrogen bonds. Chain-ends' resonances could however not be identified by ${ }^{1} \mathrm{H}$ NMR analysis, thus precluding the estimation of the PA molar mass but arguing for the formation of high molar mass materials. Correspondingly, the comparison between the ${ }^{13} \mathrm{C}\left\{{ }^{1} \mathrm{H}\right\}$ spectrum of both starting materials with the J-MOD NMR spectrum of the product (Figure S20) showed the shift of $\mathrm{C}^{\mathrm{c}-\mathrm{g}}$ resonances to $\mathrm{C}^{\mathrm{c}^{\prime}-\mathrm{g}}$, assumed to result from the formation of amide functions. 
Unfortunately, the molar mass of the polymer could not be determined by SEC due to its very low solubility in classic solvents used for SEC analysis (THF, $\mathrm{CH}_{2} \mathrm{Cl}_{2}, \mathrm{DMF} / \mathrm{LiBr}, \mathrm{HFIP}$ ).

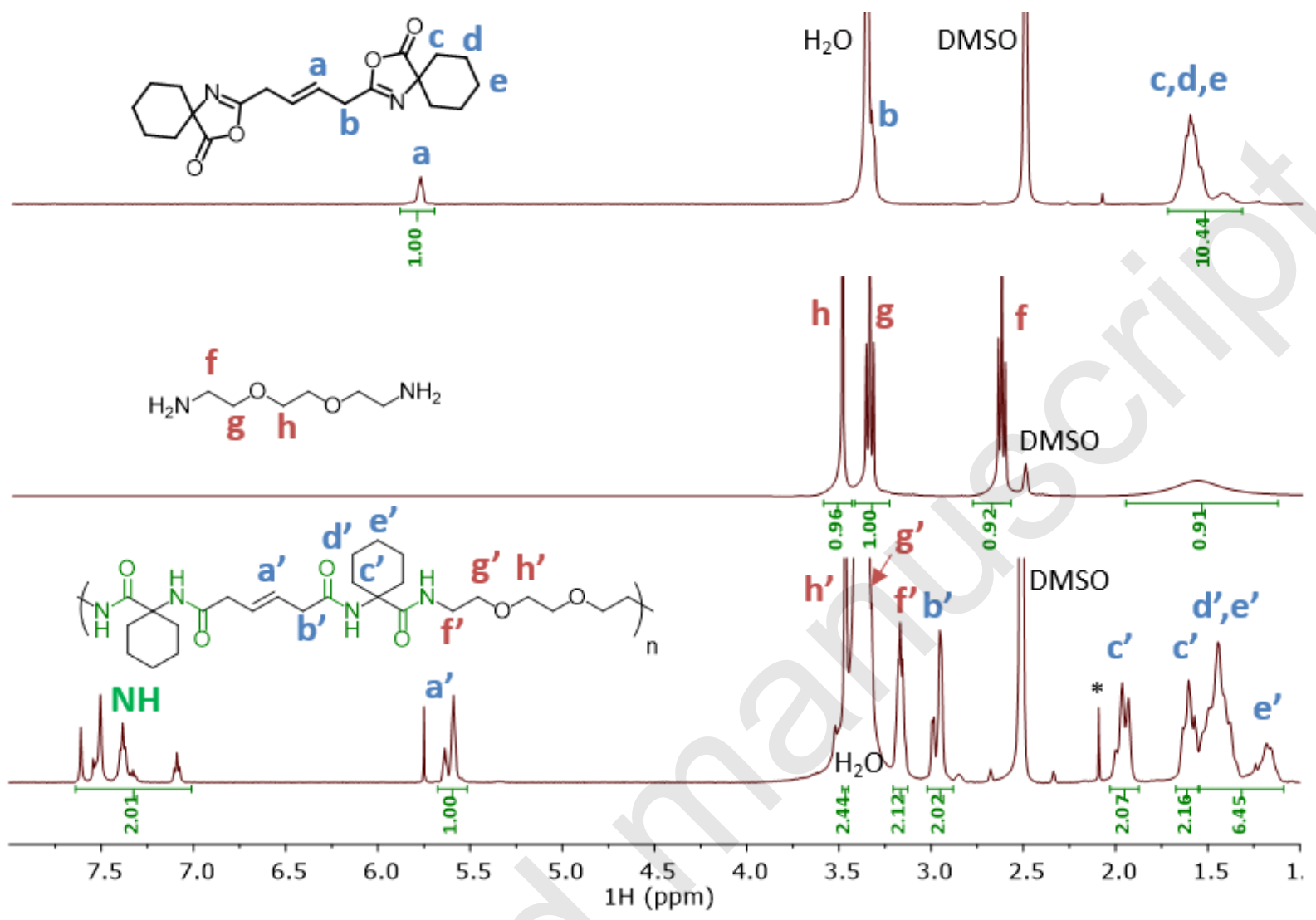

Figure 5. ${ }^{1} \mathrm{H}$ NMR spectra (400 MHz, 298 K, DMSO-d $d_{6}$ ) of CTA 3 (top), EDR-148 (middle) and the resulting PA (Scheme 6) (bottom).

ATR-FTIR analysis further supported the presence of secondary amide functions in the sample $\left(\nu\left(\mathrm{cm}^{-1}\right): 3300\right.$ (weak, broad) $\mathrm{N}-\mathrm{H}$ stretching; 1640 (strong, sharp) $\mathrm{C}=\mathrm{O}$ amide I stretching; 1520 (strong, sharp) $\mathrm{C}=\mathrm{O}$ amide II stretching; 1450 (medium, sharp) $\mathrm{C}-\mathrm{N}$ stretching), as well as of ether functions $\left(\mathrm{v}\left(\mathrm{cm}^{-1}\right)\right.$ : 1090 (strong, broad), $\mathrm{C}-\mathrm{O}$ stretching), along with the disappearance of characteristic bands of EDR-148 $\left(v\left(\mathrm{~cm}^{-1}\right): 1600\right.$ (medium, sharp) $-\mathrm{NH}_{2}$ scissoring; 840 (strong, sharp) $-\mathrm{NH}_{2}$ wagging) and of CTA $3\left(\mathrm{v}\left(\mathrm{cm}^{-1}\right): 1820\right.$ (strong, sharp) $\mathrm{C}=\mathrm{O}$ stretching; 1690 (strong, sharp) $\mathrm{C}=\mathrm{N}$ stretching) (Figure $\mathrm{S} 24$ ). 
MALDI-ToF MS analysis of the PA unambiguously evidenced the presence of a repeating unit of $m / z=506.3$ g.mol ${ }^{-1}$ corresponding to an EDR-148 and a CTA 3 moiety (i.e. having both an amine chain-end and an azlactone chain-end) from $n=0$ to $n=6$ (Figure S25).

Thermal analysis of CTA 3 and of the PA isolated from the polyaddition of CTA $\mathbf{3}$ and EDR-148 (Scheme 6) from TGA evidenced a ca. $+50{ }^{\circ} \mathrm{C}$ increase of the degradation temperature at which point $10 \%$ of the mass was lost, from $T_{\mathrm{d}}{ }^{10}=252{ }^{\circ} \mathrm{C}$ for CTA 3 to $306{ }^{\circ} \mathrm{C}$ for the PA. This is in agreement with the formation of a high molar mass material with thermally stable amide functions (Figure S26). Finally, DSC analysis clearly evidenced the formation of a semi-crystalline polymer with $T_{m}=95{ }^{\circ} \mathrm{C}, T_{c}=104{ }^{\circ} \mathrm{C}$ and $T_{g}=17{ }^{\circ} \mathrm{C}$ (Figure S27).

Structural and thermal analyses thus evidenced the synthesis, for the first time, of a PA from the polyaddition of a di(AZL) molecule CTA 3 with a diamine EDR-148. It subsequently prompted the reaction of $\alpha, \omega$-di(AZL) telechelic PO pre(co)polymers with a diamine towards the preparation of $\mathrm{PO} / \mathrm{PA}$ copolymer (vide infra).

\section{Synthesis of PO/PA copolymers from AZL telechelic prepolymers: Use of an $\alpha, \omega-\operatorname{di}(\mathrm{AZL})$ telechelic P(NB-co-CDT).}

In order to prepare PO/PA materials, we selected an $\alpha, \omega$-di(CTA 3) telechelic P(NBco-CDT) copolymer (Scheme 5), since this material is liquid and much more soluble than $\alpha, \omega$-di(CTA 3) telechelic PCOE. The $\alpha, \omega$-di(AZL) telechelic copolymer (Table 3, entry 5) was engaged in the equimolar polyaddition reaction with EDR-148 $\left(\mathrm{CH}_{2} \mathrm{Cl}_{2}, 40{ }^{\circ} \mathrm{C}, 24 \mathrm{~h}\right.$; Scheme 1). The brownish elastic solid polymer recovered, thereafter referred to as P(NB-co$\mathrm{CDT} / \mathrm{PA}$, strongly hinted at the success of the polymerization. However, due to the very low solubility of the recovered polymer sample in all common solvents (most likely arising from the hydrogen bonding ability of urethane moieties), only a small fraction of a freshly prepared 
sample turned out to dissolve in THF. Note that the similar polyaddition of $\alpha, \omega$-di(CTA 3) telechelic PCOE with a higher molar mass difunctional diamine, namely Jeffamine D-2000 (a poly(oxypropylene) diamine with 33 repeating units; provided by Huntsman Co.; primary amine content $=1.05$ mequiv. $\mathrm{g}^{-1}$ ), under similar operating conditions, was found to proceed slower and did not afford eventually a solid polymer material within a reasonable time (> $2 \mathrm{~h}$ vs 50 min with Jeffamine EDR-148). The applicative targeted criteria thus being not fulfilled (in particular the formation of a solid material from two initial liquid components), this reaction was not investigated further.

${ }^{1} \mathrm{H}$ and J-MOD NMR analyses of the small THF- $d_{8}$ soluble part of a freshly prepared $\mathrm{P}(\mathrm{NB}-\mathrm{co}-\mathrm{CDT}) / \mathrm{PA}$ was performed on the crude sample recovered before evaporation of the solvent (Figures 6,7). The signals were assigned in agreement with the expected structure depicted in Scheme 1 using combined COSY, HSQC and HMBC NMR spectra (Figures S28-S30). In particular, besides the characteristic signals of the NB and CDT segments, the shift of $\mathrm{H}^{\mathrm{c}}$ from $\delta 3.15$ to $\mathrm{H}^{\mathrm{c}^{\prime}} 2.91 \mathrm{ppm}$, and of $\mathrm{H}^{\mathrm{g}}$ from $\delta 2.64$ to $\mathrm{H}^{\mathrm{g}} 3.30 \mathrm{ppm}$, evidenced a change in the close chemical environment of these hydrogens (Figure 6). Moreover, the $\mathrm{N}-\mathrm{H}$ amide appears as several sharp signals in the range $\delta 6.8-7.4 \mathrm{ppm}$, similarly to those of the polymer recovered from the model reaction of CTA 3 with EDR-148 (vide supra); again, we assume this is possibly due to strong intra- and/or inter-molecular hydrogen bonds. Chainends could not be identified by ${ }^{1} \mathrm{H}$ NMR, most likely due to their relatively low concentration within the soluble fraction of the $\mathrm{P}(\mathrm{NB}-\mathrm{co}-\mathrm{CDT}) / \mathrm{PA}$ copolymer. 


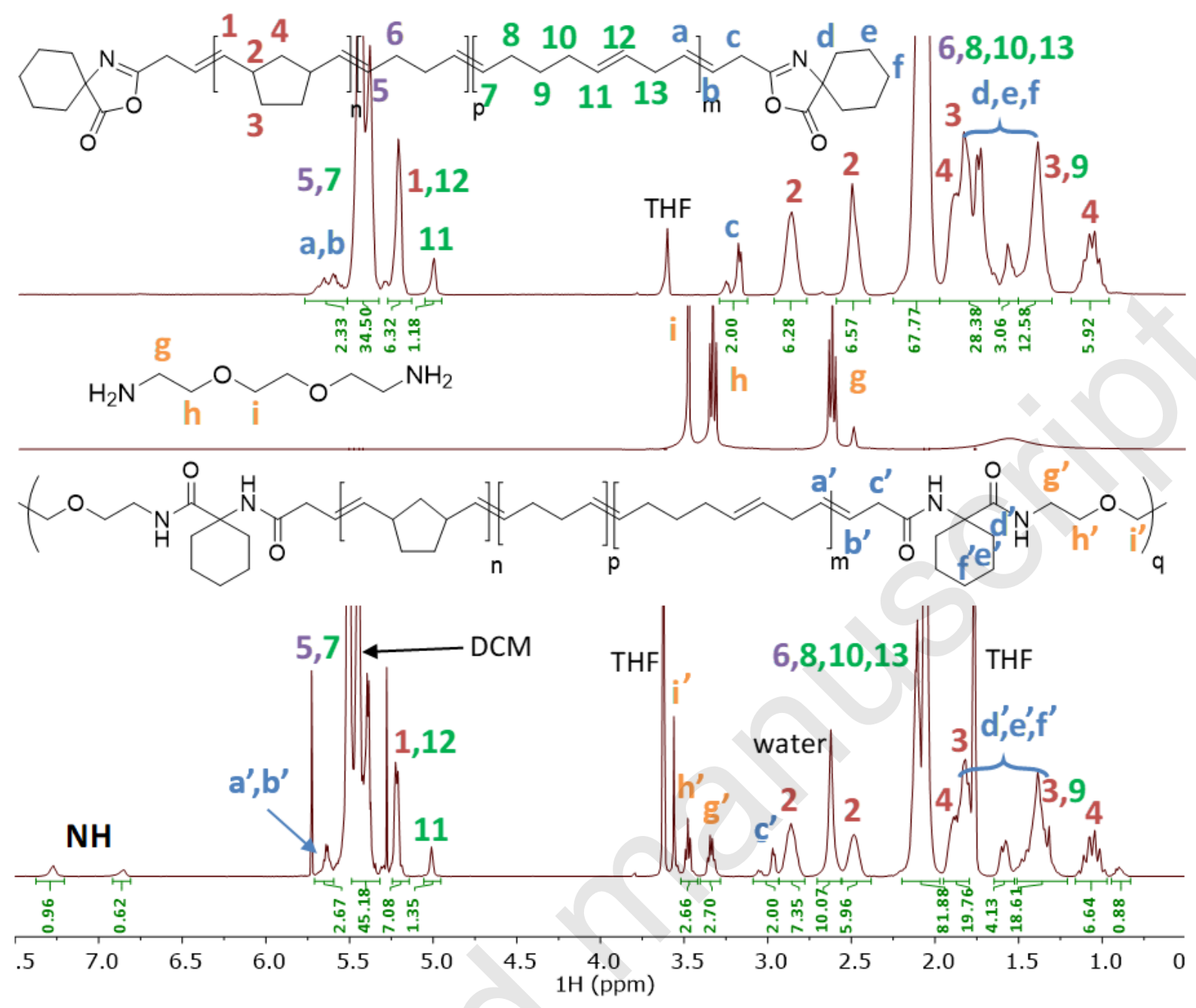

Figure 6. ${ }^{1} \mathrm{H}$ NMR spectra (400 MHz, $298 \mathrm{~K}$, THF- $\left.d_{8}\right)$ of $\alpha, \omega$-di(CTA 3) telechelic P(NB-coCDT) (top), EDR-148 (middle), and the resulting P(NB-co-CDT)/PA (bottom) (Table 3, entry $5)$.

Comparison of the ${ }^{13} \mathrm{C}\left\{{ }^{1} \mathrm{H}\right\}$ spectrum of EDR-148, and the J-MOD spectra of $\alpha, \omega-\operatorname{di}(\mathrm{CTA} 3)$ telechelic $\mathrm{P}(\mathrm{NB}-c o-\mathrm{CDT})$ and $\mathrm{P}(\mathrm{NB}-c o-\mathrm{CDT}) / \mathrm{PA}$, correspondingly showed the clear shift of $\mathrm{C}^{\mathrm{g}-1}$ and $\mathrm{C}^{\mathrm{c}}$ resonances to $\mathrm{C}^{\mathrm{g}^{\prime}-\mathrm{l}^{\prime}}$ and $\mathrm{C}^{\mathrm{c}^{\prime}}$, respectively ; this evidences an important change in the chemical structures, which we assigned to the formation of a PA (Figure 7). Some signals remained unassigned and probably resulted from the structural diversity ensuing the polymerization. 


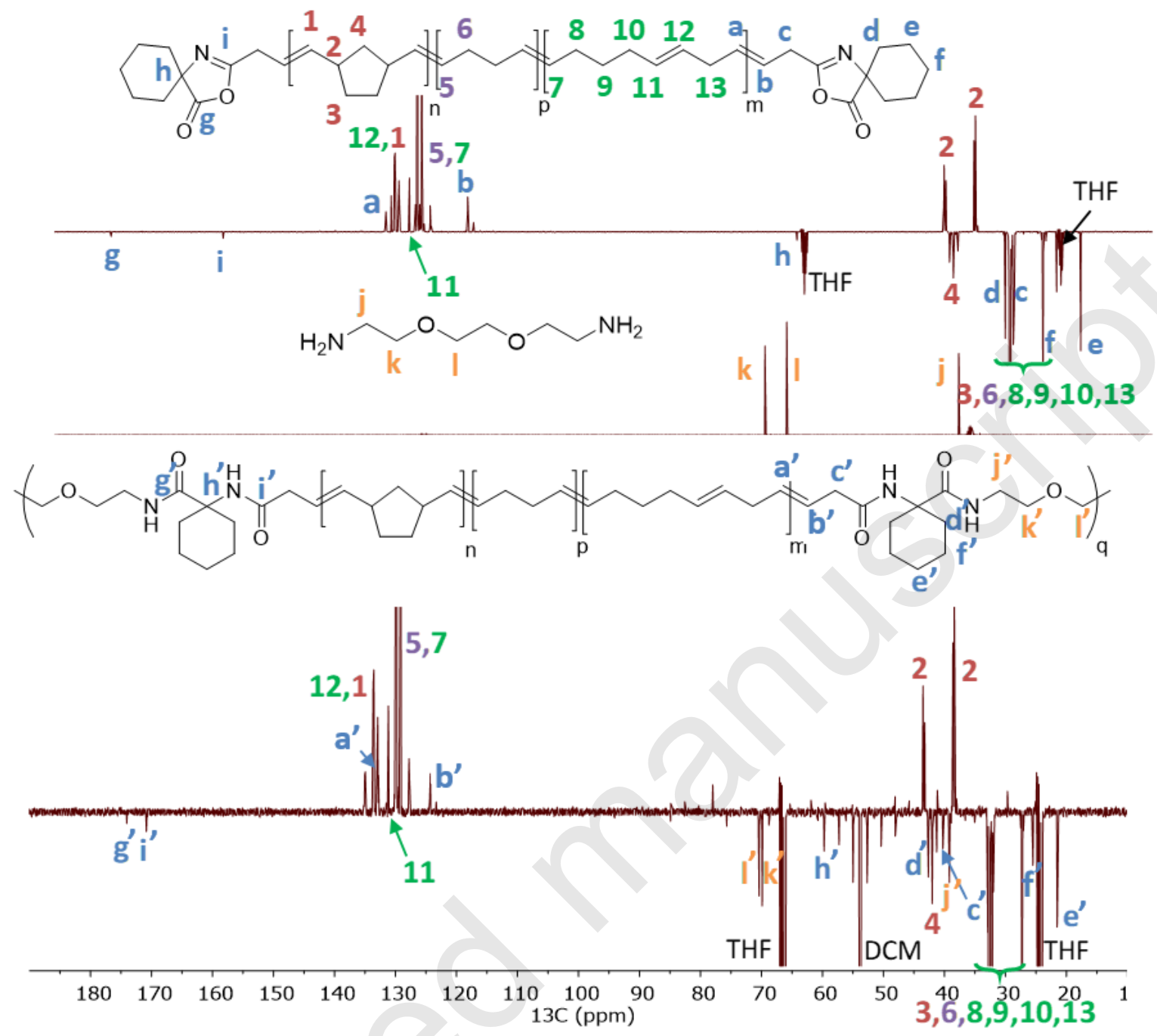

Figure 7. J-MOD NMR spectrum $\left(100 \mathrm{MHz}, 298 \mathrm{~K}\right.$, THF- $\left.d_{8}\right)$ of $\alpha, \omega$-di(CTA 3) telechelic $\mathrm{P}(\mathrm{NB}-\mathrm{co}-\mathrm{CDT})$ (top), ${ }^{13} \mathrm{C}\left\{{ }^{1} \mathrm{H}\right\}$ NMR spectrum (100 MHz, $298 \mathrm{~K}$, THF- $\left.d_{8}\right)$ of EDR-148 (middle), and J-MOD NMR spectrum (100 MHz, $298 \mathrm{~K}$, THF- $d_{8}$ ) of the resulting P(NB-coCDT)/PA (bottom) (Table 3, entry 5).

FTIR analysis of the isolated $\mathrm{P}(\mathrm{NB}-\mathrm{co}-\mathrm{CDT}) / \mathrm{PA}$ supported the presence of secondary amide functions $\left(v\left(\mathrm{~cm}^{-1}\right): 3300\right.$ (weak, broad) $\mathrm{N}-\mathrm{H}$ stretching; 1650 (strong, sharp) $\mathrm{C}=\mathrm{O}$ stretching; 1540 (strong, sharp) $\mathrm{C}=\mathrm{O}$ stretching; 1450 (strong, sharp) $\mathrm{C}-\mathrm{N}$ stretching), as well as of ether functions $\left(v\left(\mathrm{~cm}^{-1}\right): 1100\right.$ (medium, sharp) $\mathrm{C}-\mathrm{O}$ stretching), along with the 
disappearance of the characteristic bands of the $\alpha, \omega$-di(CTA 3) telechelic P(NB-co-CDT) ( $v$ $\left(\mathrm{cm}^{-1}\right): 1820, \mathrm{C}=\mathrm{O}$ stretching; 1680, $\mathrm{C}=\mathrm{N}$ stretching) (Figure 8).

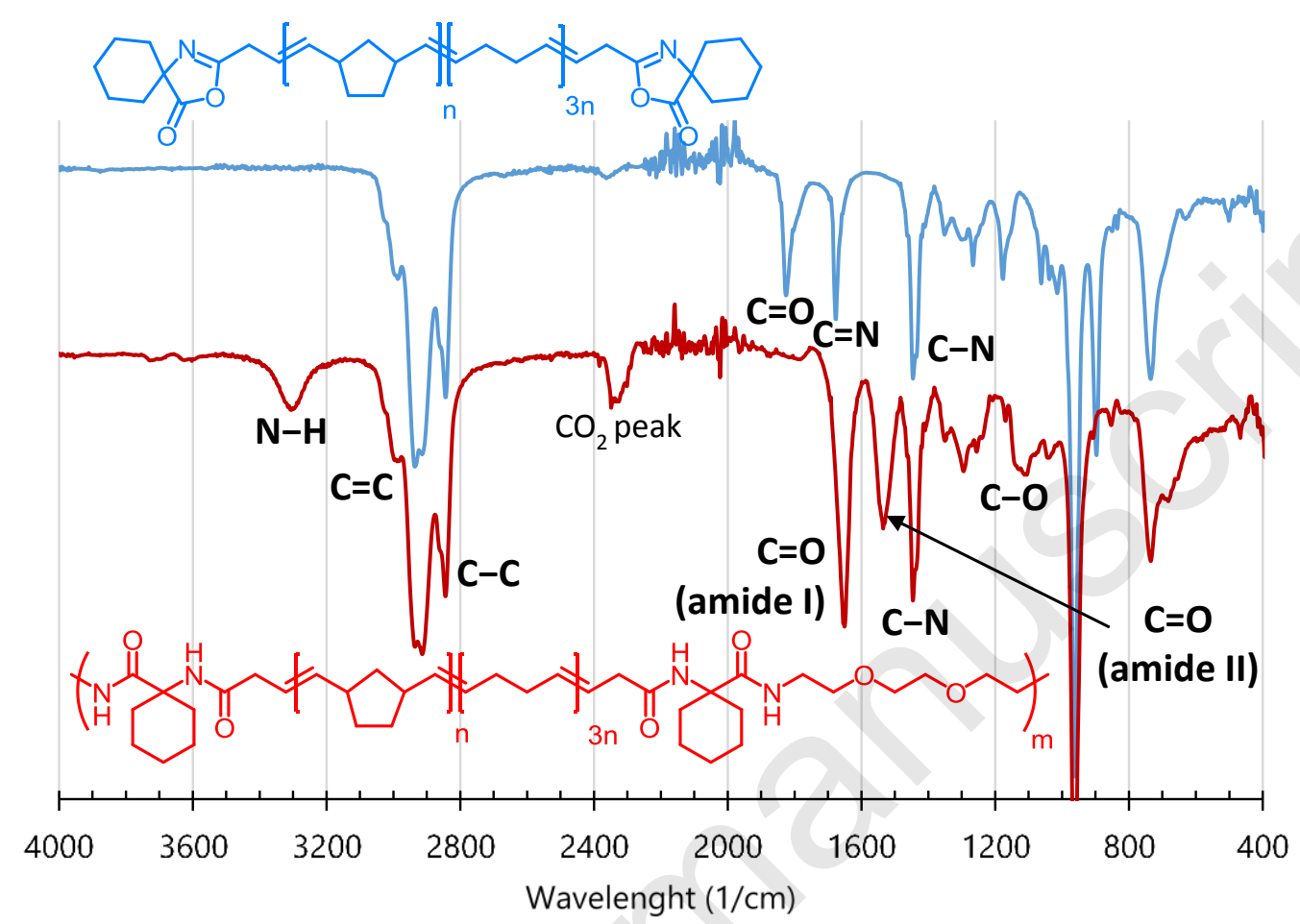

Figure 8. ATR-FTIR spectra of the $\alpha, \omega$-di(CTA 3) telechelic P(NB-co-CDT) (blue) and of the resulting $\mathrm{P}(\mathrm{NB}-\mathrm{co}-\mathrm{CDT}) / \mathrm{PA}$ (red) (Table 3, entry 5).

SEC analysis in THF of the small soluble fraction of the crude sample revealed a significant increase of the molar mass value $\left(M_{\mathrm{n}, S E C}=15000 \mathrm{~g} \cdot \mathrm{mol}^{-1}\right)$ for $\mathrm{P}(\mathrm{NB}-\mathrm{co}-\mathrm{CDT}) / \mathrm{PA}$ as compared to the precursor $\left(\mathrm{M}_{\mathrm{n}, S E C}=7600 \mathrm{~g} \cdot \mathrm{mol}^{-1}\right)$. However, due to the poor solubility of the polymer sample as above-mentioned, only the lower molar mass fraction of the polymer, typically dimers, were detected by SEC analysis. Unfortunately, no other regular solvent used for $\mathrm{SEC}\left(\mathrm{CH}_{2} \mathrm{Cl}_{2}, \mathrm{DMF}+\mathrm{LiBr}, \mathrm{DMF}+\mathrm{HFIP}\right)$ could solubilize the prepared material. Thus, SEC analysis was not representative of the real molar mass values and dispersity.

TGA analyses of $\alpha, \omega-\operatorname{di}(\mathrm{CTA} 3) \mathrm{P}(\mathrm{NB}-c o-\mathrm{CDT})$ and $\mathrm{P}(\mathrm{NB}-c o-\mathrm{CDT}) / \mathrm{PA}$ under nitrogen revealed a similar degradation temperature $\left(T_{\mathrm{d}}{ }^{10 \%}=337^{\circ} \mathrm{C}, T_{\mathrm{d}}{ }^{50 \%}=450{ }^{\circ} \mathrm{C}\right)$ for both polymers (Figure S31). We assume this is probably because the amount of amide functions 
within the PO/PA copolymer is too low to impact its thermal resistance to degradation. DSC analyses of $\mathrm{P}(\mathrm{NB}-\mathrm{co}-\mathrm{CDT}) / \mathrm{PA}$ under air did not show any melting or crystallization temperature in the range $-100{ }^{\circ} \mathrm{C}-300{ }^{\circ} \mathrm{C}$ (Figure S32). However, an exotherm was observed from $0{ }^{\circ} \mathrm{C}$ to $250{ }^{\circ} \mathrm{C}$ in the first heating cycle, suggesting a chemical reaction, possibly due to cross-linking and/or oxidation of the polymer. A glass transition was possibly observed at $T_{\mathrm{g}}$ $=97{ }^{\circ} \mathrm{C}$.

\section{Conclusion}

The straightforward synthesis of azlactone telechelic (co)POs is reported by a combination of ROMP/CM/RCM polymerization of $\mathrm{COE}$, or of CDT/NB, catalyzed by $\mathbf{G} \mathbf{2}$ in the presence of azlactone functional alkene CTAs. The use of symmetric AZL functional CTAs 1-3 selectively affords well-defined $\alpha, \omega$-di(AZL) telechelic PCOEs and $\alpha, \omega$-di(AZL) telechelic $\mathrm{P}(\mathrm{NB}-\mathrm{co}-\mathrm{CDT}) \mathrm{s}$; the corresponding cyclic (co)polymers were formed only in minor amounts (<ca. 20wt\%). Subsequently, the polyaddition reaction of the azlactone end-capping moiety of such prepolymers with EDR-148 diamine enabled the preparation of original PA materials under mild operating conditions $\left(\mathrm{CH}_{2} \mathrm{Cl}_{2}, 40{ }^{\circ} \mathrm{C}\right.$, catalyst free).

Overall, this work establishes both the first reported preparation of $\alpha, \omega$-di(AZL) telechelic polymers, and a new synthetic strategy to PO-based PAs from the one-pot polyaddition of such di(AZL)end-capped polymers with a diamine. More generally, the tandem ROMP/CM/RCM approach using AZL functional CTAs may be next extended to a wide range of cyclic olefins. 


\section{ASSOCIATED CONTENT}

\section{Supporting Information}

The Supporting Information is available free of charge on the ACS Publications website at

DOI: to be completed

Complementing experiments, and complementing characterization of CTAs, PCOEs, P(NB-co-CDT) and PAs, including 1D and 2D NMR spectra, FTIR spectra, MALDI-ToF mass spectra, DSC and TGA analyses.

\section{AUTHOR INFORMATION}

Corresponding Authors

*E-mail jean-francois.carpentier@univ-rennes1 (JF.C.); sophie.guillaume@univ-rennes1.fr (S.M.G.)

\section{ORCID}

Jean-François Carpentier :

0000-0002-9160-7662

Sophie M. Guillaume :

0000-0003-2917-8657

\section{Notes}

The authors declare no competing financial interest.

\section{Acknowledgements}

Financial support of this research by Bostik (Ph.D. grants to C.C. and E.V.) is gratefully acknowledged. P. Jéhan (CRMPO-Scanmat) and T. Roisnel (ISCR) are gratefully acknowledged for MS and X-ray diffraction analyses, respectively. 


\section{References}

1 Horie, K.; Barón, M.; Fox, R. B.; He, J.; Hess, M.; Kahovec, J.; Kitayama, T.; Kubisa, P.; Maréchal, E.; Mormann, W.; Stepto, R. F. T.; Tabak, D.; Vohlídal, J.; Wilks E. S.; Work. W. J. Definitions of terms relating to reactions of polymers and to functional polymeric materials (IUPAC Recommendations 2003). Pure Appl. Chem., 2004, 76, 889-906.

2 Yagci, Y.; Nuyken, O.; Graubner, V.-M. in Encyclopedia of Polymer Science and Technology (4th Edition), Ed. H. F. Mark, Wiley, 2014, 13, 671-744.

3 Yagci, Y.; Nuyken, O.; Graubner, V. in Encylopedia of Polymer Science, 3rd ed., J. I. Kroschwitz, Ed., Wiley, New York, 2005, 12, 57-130.

4 Tasdelen, M. A.; Kahveci, M. U.; Yagci, Y. Telechelic Polymers by Living and Controlled/Living Polymerization Methods. Prog. Polym. Sci., 2011, 36, 455-567.

5 Quirk. R. P. Controlled End-Group Functionalization (Including Telechelics) Polym. Sci.: A comprehensive Ref., 2012, 6, 351-412.

6 Handbook of telechelic polyesters, polycarbonates and polyethers, S. M. Guillaume Ed., 2017 Pan Stanford Publishing Pte. Ltd.

7 Franssen, N. M. G.; Reek, J. N. H.; de Bruin, B. Synthesis of functional 'polyolefins': state of the art and remaining challenges. Chem. Soc. Rev., 2013, 42, 5809-5832.

Martinez, H.; Ren, N.; Matta, M. E.; Hillmyer, M. Ring-opening metathesis polymerization of 8-membered cyclic olefin. Polym. Chem. 2014, 5, 3507-3532.

Hilf, S.; Kilbinger, A. F. M. Functional end groups for polymers prepared using ringopening metathesis polymerization. Nat. Chem., 2009, 1, 537-546.

Amin, S. B.; Marks, T. J. Angew. Chem. Int. Ed., 2008, 47, 2006

11 Maughon, B. R.; Morita, T.; Bielawski, C. W.; Grubbs, R. H. Synthesis of Crosslinkable Telechelic Poly(butenylene)s Derived from Ring-Opening Metathesis Polymerization. Macromolecules 2000, 33, 1929-1935.

12 Vanbiervliet, E.; Fouquay, S.; Michaud, G.; Simon, F.; Carpentier, J.-F.; Guillaume, S. M. From Epoxide to Cyclodithiocarbonate Telechelic Polycyclooctene through ChainTransfer Ring-Opening Metathesis Polymerization (ROMP): Precursors to NonIsocyanate Polyurethanes (NIPUs). Macromolecules, 2017, 50, 69-82. 
Morita, T.; Maughon, B. R.; Bielawski, C. W.; Grubbs, R. H. A Ring-Opening Metathesis Polymerization (ROMP) Approach to Carboxyl- and Amino-Terminated Telechelic Poly(butadiene)s. Macromolecules 2000, 33, 6621-6623.

Martinez, H.; Hillmyer, M. Carboxy-Telechelic Polyolefins in Cross-Linked Elastomers. Macromolecules 2014, 47, 479-485.

Bielawski, C. W.; Scherman, O. A.; Grubbs, R. H. Highly efficient syntheses of acetoxy- and hydroxy-terminated telechelic poly(butadiene)s using ruthenium catalysts containing N-heterocyclic ligands. Polymer 2001, 42, 4939-4945.

Bielawski, C. W.; Benitez, D.; Morita, T.; Grubbs, R. H. Synthesis of EndFunctionalized Poly(norbornene)s via Ring-Opening Metathesis Polymerization. Macromolecules 2001, 34, 8610-8618.

Annunziata, L.; Fouquay, S.; Michaud, G.; Simon, F.; Guillaume, S. M.; Carpentier, J.F. Mono- and di-cyclocarbonate telechelic polyolefins synthesized from ROMP using glycerol carbonate derivatives as chain-transfer agents. Polym. Chem. 2013, 4, 13131316.

Diallo, A. K.; Annunziata, L.; Fouquay, S.; Michaud, G.; Simon, F.; Brusson, J.-M.; Guillaume, S. M. Carpentier, J.-F. Ring-opening metathesis polymerization of cyclooctene derivatives with chain transfer agents derived from glycerol carbonate. Polym. Chem. 2014, 5, 2583-2591.

Chung, T. C.; Chasmawala, M. Synthesis of telechelic 1,4-polybutadiene by metathesis reactions and borane monomers. Macromolecules 1992, 25, 5137-5144.

Hillmyer, M. A.; Grubbs, R. H. Preparation of hydroxytelechelic poly(butadiene) via ring-opening metathesis polymerization employing a well-defined metathesis catalyst. Macromolecules 1993, 26, 872-874.

22 Hillmyer, M. A.; Grubbs, R. H. Chain Transfer in the Ring-Opening Metathesis Polymerization of Cyclooctadiene Using Discrete Metal Alkylidenes. Macromolecules 1995, 28, 8662-8667.

23 Hillmyer, M. A.; Nguyen, S. T.; Grubbs, R. H. Utility of a Ruthenium Metathesis Catalyst for the Preparation of End-Functionalized Polybutadiene. Macromolecules 1997, 30, 718-721.

24 Fraser, C.; Hillmyer, M. A.; Gutierrez, E.; Grubbs, R. H. Degradable Cyclooctadiene/Acetal Copolymers: Versatile Precursors to 1,4-Hydroxy-telechelic 
Polybutadiene and Hydroxy-telechelic Polyethylene. Macromolecules, 1995, 28, 72567261.

Thomas, M. R.; Grubbs, R. H. Synthesis of Telechelic Polyisoprene via Ring-Opening Metathesis Polymerization in the Presence of Chain Transfer Agent. Macromolecules 2010, 43, 3705-3709.

Pitet, L. M.; Hillmyer, M. Combining Ring-Opening Metathesis Polymerization and Cyclic Ester Ring-Opening Polymerization To Form ABA Triblock Copolymers from 1,5-Cyclooctadiene and D,L-Lactide. Macromolecules 2009, 42, 3674-3680.

Pitet, L. M.; Chamberlain, M. M.; Hauser, A. W.; Hillmyer, M. Synthesis of Linear, HShaped, and Arachnearm Block Copolymers By Tandem Ring-Opening Polymerizations. Macromolecules 2010, 43, 8018-8025.

Amendt, M. A.; Pitet, L. M.; Moench, S.; Hillmyer, M. Reactive triblock polymers from tandem ring-opening polymerization for nanostructured vinyl thermosets. Polym. Chem. 2012, 3, 1827-1837.

Wang, Y.; Hillmyer, M. Hydroxy-telechelic poly(ethylene-co-isobutylene) as a soft segment for thermoplastic polyurethanes. Polym. Chem. 2015, 6, 6806-6811.

Ji, S.; Hoye, T. R.; Macosko, C. W. Diamino Telechelic Polybutadienes for Solventless Styrene-butadiene-styrene (SBS) Triblock Copolymer Formation. Polymer 2008, 49, 5307-5313.

31 Ji, S.; Hoye, T. R.; Macosko, C. W. Controlled Synthesis of High Molecular Weight Telechelic Polybutadienes by Ring-Opening Metathesis Polymerization. Macromolecules 2004, 37, 5485-5489.

Michel, X.; Fouquay, S.; Michaud, G.; Simon, F.; Brusson, J.-M.; Carpentier, J.-F.; Guillaume, S. M. $\alpha, \omega$-Bis(trialkoxysilyl) difunctionalized polycyclooctenes from ruthenium-catalyzed chain-transfer ring-opening metathesis polymerization. Polym. Chem. 2016, 7, 4810-4823.

Diallo, A. K.; Michel, X.; Fouquay, S.; Michaud, G.; Simon, F.; Brusson, J.-M.; Carpentier, J.-F.; Guillaume, S. M. $\alpha$-Trialkoxysilyl Functionalized Polycyclooctenes Synthesized by Chain-Transfer Ring-Opening Metathesis Polymerization. Macromolecules 2015, 48, 7453-7465.

Michel, X.; Fouquay, S.; Michaud, G.; Simon, F.; Brusson, J.-M.; Roquefort, P.; Aubry, T.; Carpentier, J.-F.; Guillaume, S. M. Tuning the properties of $\alpha, \omega$-bis(trialkoxysilyl) 
telechelic copolyolefins from ruthenium-catalyzed chain-transfer ring-opening metathesis polymerization (ROMP). Polym. Chem., 2017, 8, 1177-1187.

Michel, X.; Fouquay, S.; Michaud, G.; Simon, F.; Brusson, J.-M.; Carpentier, J.-F.; Guillaume, S. M. Simple access to alkoxysilyl telechelic polyolefins from rutheniumcatalyzed cross-metathesis depolymerization of polydienes. Eur. Polym. J., 2017, 96, 403-413.

Buck, M. E.; Lynn, D. M. Azlactone-functionalized polymers as reactive platforms for the design of advanced materials: Progress in the last ten years. Polym. Chem. 2012, 3, $66-80$.

Ho, H. T.; Levere, M. E.; Fournier, D.; Montembault, V.; Pascual, S.; Fontaine, L. Introducing the Azlactone Functionality into Polymers through Controlled Radical Polymerization: Strategies and Recent Developments. Aust. J. Chem., 2012, 65, 970977.

Heilmann, S. M.; Rasmussen, J. K.; Krepski, L. R. Chemistry and technology of 2-alkenyl azlactones. J. Polym. Sci A: Polym. Chem. 2001, 39, 3655-3677. de Castro, P. P.; Carpanez, A. G.; Amarante, G. W. Azlactone Reaction Developments. Chem. Eur. J., 2016, 22, 10294-10318.

Engler, D. A.; Maistrovich, A. R. Continuous Process for Making Polymers Having Pendant Azlactone or Macromolecular Moieties, 1984, US4695608A.

Wang, X.; Davis, J. L.; Aden, B. M.; Lokitz, B. S.; Kilbey, S. M. Versatile Synthesis of Amine-Reactive Microgels by Self-Assembly of Azlactone-Containing Block Copolymers, Macromolecules, 2018, 51, 3691-3701.

Lapinte, V.; Fontaine, L. ; Campistron, L. ; Reyx, D. Ring-opening metathesis polymerization (ROMP) of isomerically pure functional monomers and acyclic diene metathesis depolymerization (retro-ADMET) of functionalized polyalkenamers. J. Mol. Cat. A: Chem., 2002, 190, 117-129.

43 Lapinte, V.; Brosse, J. C. ; Fontaine, L. Synthesis and ring-opening metathesis polymerization (ROMP) reactivity of endo- and exo-norbornenylazlactone using ruthenium catalysts. Macromol. Chem. Phys., 2004, 205, 824-833. Telechelic Polymer, 2004, US Pat. 7332546B2. Page, I. B. Polyamides as Engineering Thermoplastic Materials, 2000. 
$47 \quad$ Schlack, P. Preparation of Polyamides, 1938, US2241321A.

48 Matthies P., Seydl W. F. History and Development of Nylon 6. In: High Performance Polymers: Their Origin and Development; Seymour R.B., Kirshenbaum G.S. (eds); Springer, Dordrecht, 1986.

Aharoni, S. M. Nylons: Their Synthesis, Structure, and Properties, J. Wiley \& Sons, 1997.

Page, I. B. Polyamides as Engineering Thermoplastic Materials, in Rapra Review Report $N^{\circ} 121,2000,11(1)$; Rapra Technology Ltd.

Herzog, B.; Kohan, M. I.; Mestemacher, S. A.; Pagilagan, R. U.; Redmond, K. Polyamides, in Ullmann's Encyclopedia of Industrial Chemistry; John Wiley and Sons, 2013.

Winnackera, M. Polyamides and their functionalization: recent concepts for their applications as biomaterials. Biomater. Sci., 2017, 5, 1230-1235.

Taylor, L. D.; Platt, T. E. The chemistry of 2-alkenyl-5(4H)-oxazolones. VIII acidcatalyzed reaction with alcohols. J. Polym. Sci., Polym. Lett. Ed. 1969, 7, 597-603.

ROHM \& HAAS, Patent FR1596614, 1970.

Hogan, J. C.; Coruzzi, L. A. WO94/00509, 1994.

Matta, M. S.; Andracki, M. E. Rate-controlling step of oxazolinone formation. Secondary and solvent kinetic isotope effects. J. Am. Chem. Soc. 1985, 107, 6036-6039. Gorodisher, I.; Pocius, A. V.; Gaddam, N. B.; Hansen, R. G. Pat. WO2010/011714 A2, 2010.

Stierli, D.; Harald, W.; Rajan, R. Pat. WO2009/127722 Al, 2009.

Sato, H.; Okimoto, K.; Tanaka, Y. Polymerization of 5-Substituted Cyclooctenes with Tungsten and Molybdenum Catalysts J. Macromol. Sci., Part A: Chem., 1977, 11, 767778.

60 Dounis, P.; Feast, W. J.; Kenwright, A. M. Ring-opening metathesis polymerization of monocyclic alkenes using molybdenum and tungsten alkylidene (Schrock-type) initiators and $13 \mathrm{C}$ nuclear magnetic resonance studies of the resulting polyalkenamers. Polymer, 1995, 36, 2787-2796. 